\title{
Reforming Legislatures: \\ Is one House better than two?
}

\author{
GIOVANNI FACCHINI \\ CECILIA TESTA
}

CESIFO WORKING PAPER NO. 2659

CATEgory 2: Public ChOICE

MAY 2009
An electronic version of the paper may be downloaded
- from the SSRN website: Www.SSRN.com
- from the RePEc website: $\quad$ www.RePEc.org
- from the CESifo website: www.CESifo-group.org/wp




\title{
Reforming Legislatures: Is one House better than two?
}

\begin{abstract}
During the last decade unicameral proposals have been put forward in fourteen US states. In this paper we propose a theoretical framework casting some lights on the drawbacks of bicameral state legislatures and on the effects of the proposed constitutional reforms. In a setting where lawmakers interact with a lobby through a bargaining process and with voters by means of elections, we show that when time constraints are binding, bicameralism might lead to a decline in the legislator's bargaining power vis-à-vis the lobby and to a reduction in his electoral accountability. On the other hand, when the time constraint is not binding, bicameralism might improve electoral accountability. Hence, arguments suggesting that bicameralism is a panacea against the abuse of power by elected legislators should be taken with due caution and the proposed unicameral reforms in US states may indeed reduce corruption levels among elected representatives.
\end{abstract}

JEL Code: D72, C78, H19.

Keywords: bicameralism, corruption, lobbying, bargaining, elections.

Giovanni Facchini

Department of Economics

Erasmus University Rotterdam

PO Box 1738

3000 DR Rotterdam

The Netherlands

facchini@ese.eur.nl

\author{
Cecilia Testa \\ Department of Economics \\ Royal Holloway University of London \\ Egham, Surrey TW20 0EX \\ United Kingdom \\ cecilia.testa@rhul.ac.uk
}

May 19, 2009

We would like to thank assemblyman Richard L. Brodsky from the New York State Assembly for sharing with us the text of the Bill A597 (January 18 2005). We also wish to thank the participants of the Latin American Econometric Society meeting (Salvador de Bahia), the North American Econometric Society meeting (Chicago), the Midwest Political Science Association meeting (Chicago), the PSPE conference "Designing Democratic Institutions" (London School of Economics and Political Science) for useful comments. 
"A unicameral legislature will cut government expense, increase the legislators accountability to their constituents and improve efficiency." Ventura (1998)

\section{Introduction}

During the last two decades, rampant corruption scandals and a generalized increase in the State debt have cast dark shadows on the accountability of state legislators across the United States. ${ }^{1}$ This has fostered a widespread debate on the effectiveness of current bicameral arrangements, leading to the formulation of unicameral proposals in fourteen US states (Rogers 1999), the two most recent ones having been put forward in California and New York. Only the years of the great depression have witnessed a similar level of unicameral initiatives, which culminated in the decision of Nebraska, alone among all US states, to go unicameral in 1934. At that time, this decision was viewed with suspicion and the fear was that Nebraska would become a 'lobbyist's paradise'.2 The historical evidence, however, shows that this fear was unfounded (Ewing 1937; Kolasa 1971; Shumate 1952), and in fact more recent data suggest that Nebraska ranks amongst the least corrupt US states (Glaeser and Saks 2006, Corporate Crime Reporter 2004).

The lack of conclusive evidence on the advantages of bicameralism rises the fundamental question of whether the second chamber is a useless duplication of the first, as most unicameral proposals suggest, ${ }^{3}$ or whether it serves the important purpose of increasing the accountability of elected representatives. ${ }^{4}$ This controversy is not unique to US state legislatures, as shown by the ongoing constitutional debate and reforms implemented in many

\footnotetext{
${ }^{1}$ As reported by the Center for Public Integrity, over one billion dollars was spent in 2005 to lobby state politicians. Moreover, of the 2000 investigations on public corruption undertaken by the F.B.I. in 2006, most involve states and local officials (source: The New York Times May 11, 2006, F.B.I.'s Focus on Public Corruption Includes 2,000 Investigations)

${ }^{2}$ As Madison (1788) had pointed out "... a senate, as a second branch of the legislative assembly, distinct from, and dividing the power with, a first, must be in all cases a salutary check on the government. It doubles the security to the people, by requiring the concurrence of two distinct bodies in schemes of usurpation or perfidy, where the ambition or corruption of one would otherwise be sufficient"

${ }^{3}$ According to the New York unicameral bill proposal "A one house legislature will eliminate needless duplication and delay (...); it will speed up the budget process and facilitate the adoption of timely budgets" (source: State of New York, Bill Number A597, January 18 2005).

${ }^{4}$ Of course, bicameralism may also serve other purposes such as the representation of heterogenous interests that in modern democracies are associated with geographically distinct political jurisdictions such as for example, federal states. For a comprehensive view of bicameralism, see Tsebelis and Money (1997).
} 
national states. ${ }^{5}$

Do more complex legislative procedures really make lawmakers less vulnerable to lobby pressures? What are the potential costs of such lengthy procedures? The existing literature has identified legislative gridlock and status quo bias as the two main drawbacks of bicameralism (Riker 1992, Levmore 1992, Muthoo and Shepsle 2008). At the same time, there is growing anecdotal evidence on the frequency of 'Christmas Tree' appropriations or 'Walking Around Money' (WAM). These earmarks, introduced into state budgets to support projects put forward by politically connected institutions and organizations, are often passed under the threat of a government shutdown if the budget is not approved by the official deadline. ${ }^{6}$ This suggests the presence of a third potential drawback of a bicameral system: The complexity of the legislative procedure, combined with time constraints, might make elected representatives less accountable.

The purpose of this paper is to develop a theoretical framework that takes explicitly into account the role of time to assess the effects of the proposed reforms of bicameral state legislatures. Interestingly, and contrary to both the conventional wisdom and the existing literature (see in particular Diermeier and Myerson 1999), we argue that long legislative procedures - like the ones brought about by a bicameral system - may shift the balance of power in favor of private pressure groups, making a lobby's capture of politicians easier rather than more difficult. In other words, our paper is able to rationalize the widespread phenomenon of the 'Chistmas Tree' earmarks, which has been the subject of much debate in the popular press, and thus provides new arguments in support of unicameral state legislatures.

We model the law making process as a bargaining game of alternating offers involving a powerful lobby and law makers. This setting allows us to explicitly consider the time necessary to pass legislation and to analyze the role of time constraints in the form of a finite number of rounds. ${ }^{7}$ In our framework, a lobby can bribe the policy maker during the

\footnotetext{
${ }^{5}$ For an overview of bicameral arrangements in national states and a cross-country empirical analysis on bicameralism and corruption, see Testa (2009)

${ }^{6}$ For instance during the weeks preceding the approval of the 2005 New York state budget, it has been pointed out that "...winning on time passage from the legislature could be costly.... It might require Mr. Pataki to agree to hundreds of millions of dollars in extra spending" (The Calendar vs. the Purse for Albany's Big 3 The New York Times, March 16 2005). Notice that for most US federal states failure to approve the budget by the mandated deadline often implies a complete government shutdown. For more details on late budget procedures in US federal states see Eckl (1998).

${ }^{7}$ For a general analysis of time constraints in legislative bargaining in the form of finite bargaining rounds see Bernheim et al. (2006).
} 
legislative process, while citizens can only punish/reward him during an election called at the end of the mandate. Comparing the effectiveness of unicameral and bicameral arrangements, we find that bicameralism does not necessarily improve accountability because, by increasing the time necessary to pass legislation, it may prevent legislators from credibly threatening the rejection of lobby proposals to extract surplus from the interest group. Thus, when legislators vote sequentially on a bill, an increase in the number of veto players does not necessarily make lobbying more expensive. In contrast to Diermeier and Myerson (1999), we find that the cost of buying legislators (the so called external hurdle factor) does not increase monotonically with the number of legislative bodies. This result delivers an important warning on the optimal allocation of legislative power from the point of view of voters: The fragmentation of decision making across multiple bodies may weaken legislators, rendering lobby capture easier. Our analysis thus provides new theoretical support for the proposed unicameral reforms that are being discussed in many US states, highlighting the potential benefits of unicameralism when legislators operate under binding time constraints like in the case of the yearly budget approval.

On the other hand, when time constraints are not binding, bicameralism can have a positive effect on accountability depending on the alternative legislative procedures adopted. In particular, the best bicameral system is the one in which equal decision powers are given to the two chambers (open rule with restricted amendment rights). The system that attributes unrestricted amendment rights to the second chamber is bad for incentives, as it is likely to generate a status quo bias. The closed rule system - assigning proposal power to the first legislator and veto power to the second - can instead be ranked between the two previous alternatives.

Bicameralism is the subject of a recent, growing literature. Diermeier, Erasalan, and Merlo (2003) and Druckman and Thies (2002) have studied the impact of multiple chambers on the formation and stability of coalitional governments. Bradubury and Crain (2001) and Heller (2001) have considered instead the link between bicameralism and budget deficit. All these studies do not analyze the impact of parliamentary structures on accountability, which is instead the focus of our paper.

In order to combine elections, lobbying and legislative procedures, we extend the bar- 
gaining literature ${ }^{8}$ endogenizing the identity of one of the players (the legislator), through the introduction of an election stage. ${ }^{9}$ As in Bernheim et al. (2006), we assume that the number of bargaining rounds is finite, but differently from them we focus on the negotiations taking place between lobby and legislators, rather than on bargaining among legislators. In particular, similarly to Diermeier and Myerson (1999) and Groseclose and Snyder (1996), we assume that a lobbyist can buy the legislators' vote to obtain the implementation of a given policy and we study how constitutional rules, affecting the bargaining process, have an impact on the cost of buying legislators (external hurdle factor). However, while Diermeier and Myerson (1999), taking the external hurdle factor as given, primarily focus on how legislators can manipulate the internal organization of chambers (i.e. internal hurdle factor) to extract higher payments from lobbyists, in our work we concentrate on constitutional rules themselves to ask which institutional arrangements can prevent lobbyists and legislators from finding agreements on policies that are detrimental to voters. Hence, in our model a lobby competes with voters (rather than with other interest groups) to sway the policy choice in its favor. Considering voters is crucial because, as it has been pointed out by McKelvey and Riezman (1992), re-election incentives, together with the internal organization of chambers, have an important effect on policy outcomes. More generally, a large body of literature has stressed the importance of electoral incentives when legislators are not willing to compromise on (at least) some dimension of the policy space (Alesina 1988, Besley and Coate 1997, Grossman and Helpman 1996, Osborne and Slivinski 1996), and there is substantial empirical evidence supporting the view that elected officials pursue ideological goals (Ansolabehere et al. 2001, Levitt 1996, Poole and Rosenthal 1996). ${ }^{10}$ Hence, in a setting where legislators value re-election as a tool to implement their own ideological agenda, our analysis highlights how different parliamentary arrangements can provide incentives to ideological representatives, which respond to both voters and lobbyists. Furthermore, by providing a theoretical framework that shows how legislative rules and voting can be instru-

\footnotetext{
${ }^{8}$ See Osborne and Rubinstein (1990) for a comprehensive survey, and Baron and Ferejohn (1989) for a pioneering application of extensive form bargaining models to the legislative process.

${ }^{9}$ The literature on bicameral legislative bargaining typically does not incorporate elections. One exception is Muthoo and Shepsle (2008) which lay out a model of optimal constitutional choice introducing elections in a reduced form, i.e. without explicitly modeling the voting rule.

${ }^{10}$ Levitt (1996) finds that voters' preferences, senator ideology and party line all influence roll call voting of US senators, but the estimated weight of the senator own ideology in his objective function is higher than the weight of the other two variables. For an overview of the literature on politicians' motivation in the US context, see Jacobs and Shapiro (2000).
} 
mental in disciplining legislators, our approach is also very close to Persson, Roland, and Tabellini (1997). However, we depart from their contribution in two important directions. First, instead of a representative agent, we consider voters and legislators with heterogenous preferences over policies. Second, we introduce lobbying as the source of the agency problem.

The remainder of the paper is organized as follows. Section 2 outlines the model and discusses the main assumptions. In section 3 we characterize the equilibrium under unicameralism, while section 4 deals with bicameralism and accountability under both an open rule and a closed rule setting. Section 5 offers concluding remarks.

\section{The model}

Consider an economy composed of a set $\{1, \ldots, K\}$ of citizens indexed by $k$ who delegate to a citizen/policy-maker denoted by $g$ the selection of a public project that will be executed by a citizen/lobby $l$ representing a firm. The public project is characterized by two dimensions: $\operatorname{cost} \mathcal{C}$ and type $a$. The total $\operatorname{cost} \mathcal{C}$ is shared by all citizens, who pay a per capita cost $C \in\left\{C^{L}, C^{H}\right\}$ with $C^{H}>C^{L}=0$. The type $a \in \mathbf{R}^{+}$of the policy is an attribute on which individuals have different preferences. We denote by $a_{g}$ the policy type delivered by legislator $g$ and by $a_{k g}$ the direct benefit arising to individual $k$. Preferences for the policy type are single peaked, concave and $a_{g g}=\max _{k} a_{k g}$. Hence, citizens can be ranked according to their most preferred policy and we denote by $m$ the median of the citizens' distribution with respect to the policy types. As in Grossman and Helpman (1996) we assume that one dimension (the type) is fixed while the other (the cost) is pliable. Therefore, the most natural interpretation of the policy type is that it represents an ideological stance on which individuals are not willing to compromise. A public project is then a triple $\mathbf{p}=\left(I, C, a_{g}\right) \in \mathbf{P}$, where $\mathbf{P}$ is the set of all possible projects. For simplicity, we will indicate by $\mathbf{p}_{0}$ the degenerate case in which no project is carried out $(I=0)$. If a project is instead implemented $(I=1)$, the citizen/lobbyist $l$ realizing it obtains a profit $\Pi(C)$ increasing in $C$ and a corresponding (net) rent $\pi(C)=[\Pi(C)-C]$. For simplicity, we assume that $\pi\left(C^{H}\right)=\pi>0$ and $\pi\left(C^{L}\right)=0$.

The public policy is chosen in a game lasting for two periods $t \in\{1,2\}$, with $\delta$ being the discount factor between them, ${ }^{11}$ where the policy maker interacts with the median voter

\footnotetext{
${ }^{11}$ We focus on a finite horizon game because it represent the most difficult scenario for electoral accountability, since in the last mandate politicians do not face elections.
} 
and the lobby. In each period $t$ a project $\mathbf{p}^{t}=\left(I, C, a_{g}\right) \in \mathbf{P}^{t}$ is realized, where $\mathbf{P}^{t}$ is the set of all possible projects available at time $t .{ }^{12}$ We start by considering the case of a parliamentary body with a single decision-maker $g$, which should be thought of as the ruling majority. The timing of the game taking place between the three players (i.e. the legislator $g$, the lobby $l$ and the median voter $m$ ) is as follows. At the beginning of the first period, an exogenously appointed legislator $g$ initiates the legislative process to select a public project, and the median voter $m$ announces his voting rule. Once the process has been initiated, but before the actual policy choice, the lobby $l$ can "bribe" the lawmaker to affect his policy decision. At the end of the first period, when the project has been realized, the median voter observes the implemented policy and casts his vote. At the beginning of the second period, the elected legislator initiates a new legislative process and the lobby $l$ can again bribe him. A project is then again chosen and the game ends. Hence, the game between legislator, lobby and median voter consists of a sequence of bargaining and voting stages that will be formally analyzed in the next two sections.

\section{$2.1 \quad$ Lobbying}

We model the lobbying activity in each period $t$ as a bargaining game of alternating offers between the lobby and the incumbent legislator. Remember that, since the "type" dimension is fixed, players can only bargain to decide the cost of the project and how to share the eventual rents.

We suppose that during each political mandate $t$, negotiation rounds $r$ take place, with $r=\{1, \ldots, n\}$, during which one player proposes a project cost and a share of the corresponding rent to the other player, who can either accept or reject the proposal. If no agreement is reached by the end of the mandate $t$, given that the legislator can implement any policy independently of the lobby, the disagreement payoffs will be determined by the policy unilaterally chosen by the legislator.

As it seems natural, we assume that the lobby initiates the game by making the first proposal. ${ }^{13}$ If the proposal is accepted, the bargaining ends with an agreement, while if the

\footnotetext{
${ }^{12}$ In the rest of the paper we will interchange the terms period and mandate.

${ }^{13}$ The recent corruption charges against Jack Abramoff, one of the most influential lobbyists in Washington, has sparkled a worldwide debate on the large amounts of resources spent to gain influence on law making. As the Washington Post (June 22, 2005) points out “(...) companies are also hiring well-placed lobbyists
} 
proposal is rejected, the bargaining goes to the next round. In each of the rounds $r>1$ a player is randomly assigned the right to make offers. To describe the structure of the game, we illustrate a portion of the extensive form in Figure 1, where $N$ is nature. Let $q$ and $(1-q)$ respectively be the probability that policy maker $g$ and lobby group $l$ make a proposal at each round $r>1$. Both probabilities are common knowledge among the parties and the extreme cases where $q=0$ or $q=1$ represent the situations in which the lobby or the legislator can make take-it-or-leave-it offers, i.e. one of the parties enjoys all the bargaining power. Therefore, the assumption of random proposers allows us to model the relationship between the bargaining power of the legislator and the lobby's ability to influence policies. In particular, we will be able to study how institutional rules may affect the bargaining power of legislators, and in which contexts the lobby will be able to exploit her first mover advantage.

Formally, we can describe the bargaining game taking place in stage $t$ as follows. Denoting by $T_{l g}^{t}$ a monetary transfer from the lobby $l$ to the legislator $g$, let $\mathbf{x}_{r}^{t} \in \mathbf{X}^{t}=\left\{\left(\mathbf{p}^{t}, T_{l g}^{t}\right)\right.$ : $\left.\pi(I, C)-T_{l g}^{t} \geq 0\right\}$ be the offer made in round $r$ of mandate $t$ and let $y_{r}^{t} \in\{$ Yes, No $\}$ be the corresponding reply. A strategy for player $k$, where $k=l, g$, is a sequence of functions $\gamma_{k}^{t}=\left\{\gamma_{k}^{t, r}\right\}_{r=1}^{n}$ where $\gamma_{k}^{t, r}=\left(\mathbf{x}_{r}^{t}, y_{r}^{t}\right)$ is the $\mathrm{r}$-th round strategy that, for any history of the game up to round $r$, prescribes a proposal $\mathbf{x}_{r}^{t}$ and a response $y_{r}^{t}$ to all possible proposals by other players. The acceptance of a proposal $\mathbf{x}_{r}^{t}$ involves the implementation of a project $\mathbf{p}^{t}$ and the payment of the monetary transfer $T_{l g}^{t}=\beta_{g}^{t} \pi(I, C)$ from lobby $l$ to legislator $g$, where $\beta_{g}^{t}$ is the share of the rents from the project paid to the legislator, while the share retained by the lobby is $\beta_{l}^{t}=1-\beta_{g}^{t}$.

The corresponding one period payoff $v_{k g}^{t}($.$) of individual k$, with $k=e, g, l$ can then be

to go on the offensive and find ways to profit from the many tax breaks, loosened regulations and other government goodies that increasingly are available." In fact, professional lobbyists are usually hired for the exclusive purpose of constantly approaching legislators to promote the interests of their clients. For more information on the lobbying industry in the US see, for example, the reports from the Center for Responsive Politics available at www.opensecrets.org. 


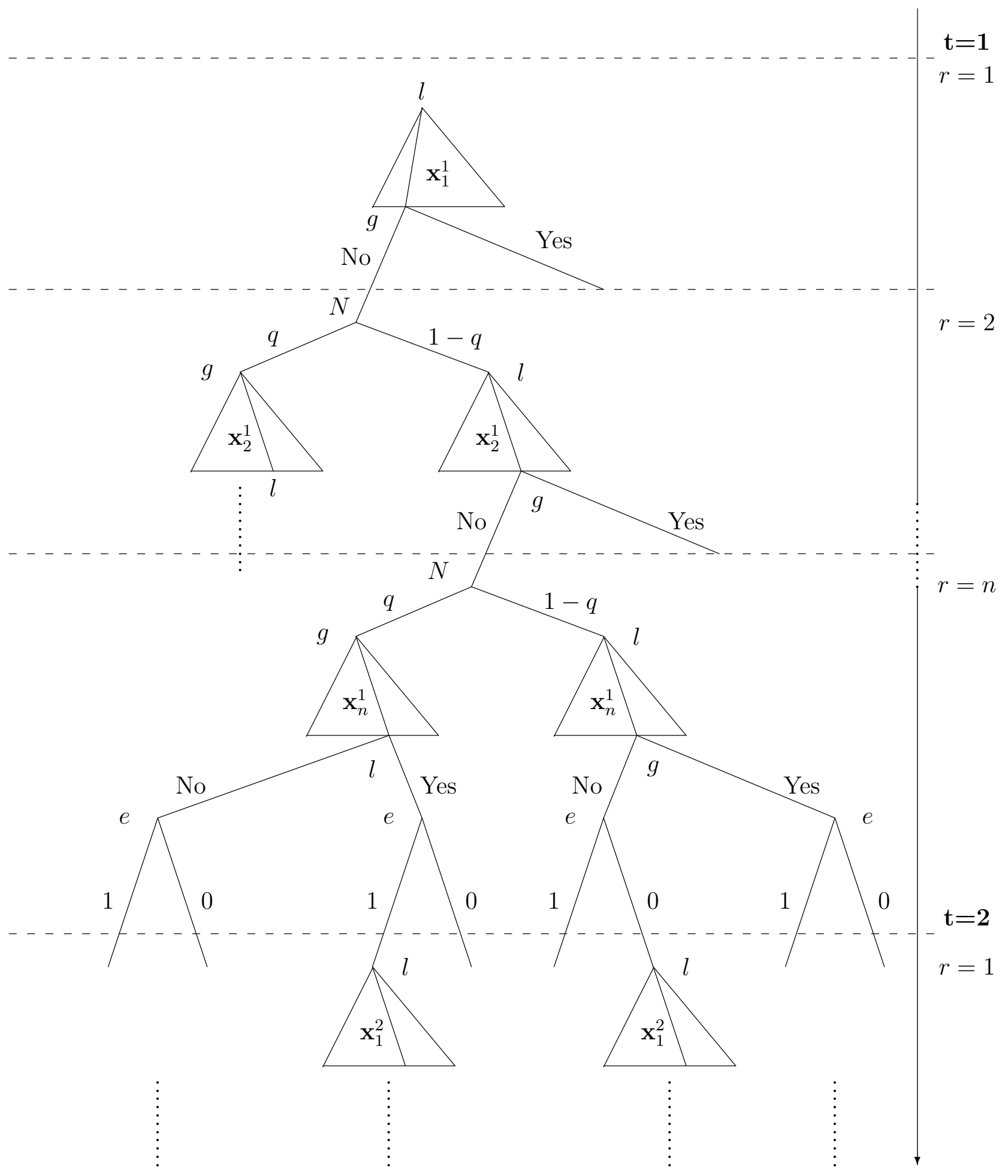

Figure 1: A unicameral system 
written as follows:

$$
\begin{aligned}
v_{k g}^{t}\left(\mathbf{p}_{0}^{t}\right) & =0 \quad \forall k \\
v_{e g}^{t}\left(\mathbf{p}_{g, C}^{t}\right) & =a_{e g}-C \\
v_{l g}^{t}\left(\mathbf{p}_{g, C}^{t}, T_{l g}^{t}\right) & =a_{l g}+\left(1-\beta_{g}^{t}\right) \pi \\
v_{g g}^{t}\left(\mathbf{p}_{g, C}^{t}, T_{l g}^{t}\right) & =a_{g g}+\beta_{g}^{t} \pi-C
\end{aligned}
$$

Throughout the paper we will focus on the situation in which citizens $e$ and the lobby $l$ have opposite interests on the policy, i.e.

$$
\begin{aligned}
v_{e g}^{t}\left(\mathbf{p}_{g, C^{H}}^{t}\right) & <v_{e g}^{t}\left(\mathbf{p}_{0}^{t}\right)<v_{e g}^{t}\left(\mathbf{p}_{g, C^{L}}^{t}\right) \quad \forall e \neq g \\
v_{e g}^{t}\left(\mathbf{p}_{0}^{t}\right) & <v_{e g}^{t}\left(\mathbf{p}_{g, C^{H}}^{t}\right)<v_{e g}^{t}\left(\mathbf{p}_{g, C^{L}}^{t}\right) \quad \forall e=g \\
v_{l g}^{t}\left(\mathbf{p}_{g, C^{H}}^{t}, T_{l g}^{t}\left(C^{H}\right)\right) & >v_{l g}^{t}\left(\mathbf{p}_{g, C^{L}}^{t}, T_{l g}^{t}\left(C^{L}\right)\right)>v_{l g}^{t}\left(\mathbf{p}_{0}^{t}\right)
\end{aligned}
$$

Note that, citizens have different ideological preferences, while they share the same taste on the cost dimension. We are now ready to introduce the voting stage.

\section{$2.2 \quad$ Voting}

For simplicity we assume that at the election stage there are only two candidates, $A$ and $B$, drawn from the set of citizens distributed according to their preferences for the policy types $a$. To avoid the trivial case where one of the candidates can win the election on purely "ideological grounds", we assume that the candidates are symmetrically located around the median voter, so that none of them enjoys an advantage on the ideological dimension of the policy. As a consequence, the cost dimension will be crucial in determining the result of the elections, i.e. it is the "politically salient" characteristic as in Besley and Coate (2003). Notice that, even if the cost $C$ is the salient issue, the second, non pliable dimension still plays an important role because candidates, who are ideological on one dimension, care about re-election as a mean to achieve their most preferred ideological stance. As we will see, ideology will affect in a non-trivial way the incentives provided by voters to legislators, since the threat of a political rival with different policy preferences can discipline the incumbent 
in his current policy choice. ${ }^{14}$

The reappointment of the incumbent $A$ at the end of the first period is challenged by the opponent $B$ and the candidate receiving the vote of the median voter wins the election. ${ }^{15} \mathrm{We}$ follow Ferejohn (1986) and assume that, to reward/punish the incumbent, at the beginning of the first period the median voter chooses a voting rule that maximizes his total utility $V_{m}(., \sigma)$, given his expectations about the legislator's behavior. Furthermore, the voting rule must be sub-game perfect, i.e. we consider only rewards/punishments that can be credibly carried out once the first period policy has been chosen, so that the voting rule is consistent with both retrospective and prospective voting. Hence, similarly to Persson, Roland, and Tabellini (1997), we focus on a simple voting rule that has the property of selecting the best possible equilibrium from the point of view of the voters and also has the advantage of being plausible. Simple retrospective voting rules, that are widely used in the political economy literature, receive substantial empirical support (Fiorina 1981) and their adoption by the electorate can be thought of as the result of simple conventions due to social norms (Persson, Roland, and Tabellini 1997).

Restricting our analysis to pure strategies, we define a voting rule for the median voter $m$ as a mapping from a policy choice $\mathbf{p}^{1} \in \mathbf{P}^{1}$ to a voting decision, $\sigma_{m}: \mathbf{P}^{1} \rightarrow\{0,1\}$, where $\sigma_{m}=1$ means that the incumbent legislator $A$ will be reelected by median voter $m$, while $\sigma_{m}=0$ indicates instead that the median voter will support the challenger $B$.

The inter-temporal utility of each individual $k$, denoted by $V_{k}$, with $k \in\{A, m, l\}$, can then be written as follows:

$$
\begin{aligned}
V_{A}\left(\gamma_{l}^{1}, \gamma_{g}^{1}, \sigma_{m}, \gamma_{l}^{2}, \gamma_{g}^{2}\right) & =v_{A A}^{1}+\delta\left[\sigma_{m} v_{A A}^{2}+\left(1-\sigma_{m}\right) v_{e B}^{2}\right] \\
V_{m}\left(\gamma_{l}^{1}, \gamma_{g}^{1}, \sigma_{m}, \gamma_{l}^{2}, \gamma_{g}^{2}\right) & =v_{m A}^{1}+\delta\left[\sigma_{m} v_{m A}^{2}+\left(1-\sigma_{m}\right) v_{m B}^{2}\right] \\
V_{l}\left(\gamma_{l}^{1}, \gamma_{g}^{1}, \sigma_{m}, \gamma_{l}^{2}, \gamma_{g}^{2}\right) & =v_{l A}^{1}+\delta\left[\sigma_{m} v_{l A}^{2}+\left(1-\sigma_{m}\right) v_{l B}^{2}\right]
\end{aligned}
$$

Since the median voter chooses a voting rule that maximizes his inter-temporal utility,

\footnotetext{
${ }^{14}$ In other words, we investigate whether non convergence to the median voter has implications for accountability. Although in this paper we do not endogenize the location, there is a vast literature showing the existence of non-convergence equilibria. See for instance Testa (2003).

${ }^{15}$ Groseclose (2007) shows that for "one and a half" dimensional preferences, i.e. preferences where voters differ in a standard left-right (ideological) dimension and share the same taste in a good-bad dimension, the majority's preferences are identical to the median voter's.
} 
given the strategies adopted by the lobby $l$ and the policy maker $g$, we can formally define the equilibrium of the voting game as follows :

Definition 1 The equilibrium of the voting game is a voting rule $\sigma_{m}^{*}$ such that, given a strategy profile $\left(\gamma_{l}^{t}, \gamma_{g}^{t}\right), V_{m}\left(., \sigma^{*},.\right) \geq V_{m}\left(., \sigma_{m},.\right), \forall \sigma_{m} \neq \sigma_{m}^{*}$.

With the further requirement that the strategies played in the bargaining game in each period $t$ satisfy subgame perfection, we are now ready to define the political equilibrium:

Definition 2 A political equilibrium is a strategy profile $\left(\gamma_{l}^{1 *}, \gamma_{g}^{1 *}, \sigma_{m}^{*}, \gamma_{l}^{2 *}, \gamma_{g}^{2 *}\right)$ such that:

i) $\left(\gamma_{l}^{2 *}, \gamma_{g}^{2 *}\right)$ is a subgame perfect equilibrium of the bargaining game in $t=2$;

ii) $\sigma_{m}^{*}$ is an equilibrium of the voting game;

iii) $\left(\gamma_{l}^{1 *}, \gamma_{g}^{1 *}\right)$ is a subgame perfect equilibrium of the bargaining game in $t=1$, given the the equilibrium strategies $\sigma_{m}^{*}$ and $\left(\gamma_{l}^{2 *}, \gamma_{g}^{2 *}\right)$.

\section{A unicameral system}

The analysis of a unicameral system constitutes a useful benchmark to evaluate how a legislator responds to monetary and electoral incentives. To address this issue, we start by characterizing the share of rents that induces him to choose the high or the low cost project. Clearly, in the two mandates, the sharing rules that implement a high cost project will be different because the legislator faces elections at the end of the first mandate only. In the second period, given a share $\beta_{g}^{2}$ and the two alternative policy choices $\mathbf{p}_{g, C^{H}}^{2}$ and $\mathbf{p}_{g, C^{L}}^{2}$, the payoffs accruing to the legislator are:

$$
\begin{aligned}
& v_{g g}^{2}\left(\mathbf{p}_{g, C^{H}}^{2}, T_{l g}^{2}\right)=a_{g g}+\beta_{g}^{2} \pi-C^{H} \\
& v_{g g}^{2}\left(\mathbf{p}_{g, C^{L}}^{2}, T_{l g}^{2}\right)=a_{g g}
\end{aligned}
$$

Therefore, any share $\beta_{g}^{2} \geq \frac{C^{H}}{\pi}$ will induce him to choose the high cost project and the equilibrium shares will depend on the bargaining power of the players, i.e. on their right to make offers. ${ }^{16}$ In the first period, the threat of losing elections might instead induce the

\footnotetext{
${ }^{16}$ Indeed, as in the standard Rubinstein game with random proposers, the equilibrium share of each player coincides with his probability of making an offer.
} 
legislator to be accountable to voters. If he chooses a low cost project, he can expect to be rewarded by voters, while if he chooses a high cost project he can be punished by the electorate and replaced by a challenger. As it is shown in the appendix (see result 1), it turns out that in equilibrium the legislator is reelected if he has chosen the low cost project or if he has decided not to carry out any project, while he is not reelected if he has chosen the high cost project. The intuition for this result is as follows. In the last period the incumbent's behavior does not depend on the voting rule because the game ends and he cannot be punished or rewarded by the voters. Hence, the voting rule that maximizes the median voter inter-temporal utility is a rule that induces the legislator to choose a policy in the voter's interest at least in the first period. A rule that punishes the incumbent if he chooses the worse policy for voters $\left(\mathbf{p}_{A, C^{H}}^{1}\right)$ and rewards him if he does not, induces the legislator to choose the low cost policy in the first period. Note that this strategy satisfies sub-game perfection since it makes the median voter (weakly) better off at any time, i.e. before and after the first period policy has been chosen. Hence, although any other voting strategy would give the voter the same utility in the second period, there is no alternative voting rule that would induce a better policy choice in the first period. Therefore, similarly to Persson, Roland, and Tabellini (1997), we adopt the Ferejohn (1986) approach that selects the voting rule delivering the best possible equilibrium from the point of voters that, in our case, corresponds to an equilibrium where accountability at least in one period can be achieved. Given this equilibrium voting strategy, the two period bargaining game can be solved by backward induction:

Lemma 1 Suppose that $q \pi \geq C^{H}$. In $t=2$ the lobby and the legislator reach an agreement in the first round of negotiation whereby the policy $\mathbf{p}_{g, C^{H}}^{2}$ is chosen, and the lobby l receives a share $\beta_{l}^{2}=(1-q)$ of the rents, while the legislator $g$ receives a share $\beta_{g}^{2}=q$. In $t=1$, given $\bar{\beta}_{A}^{1}=\delta q+\frac{C^{H}+\delta\left(a_{A A}-a_{A B}\right)}{\pi}$, in the first round of negotiation every share $\beta_{A}^{1}<\bar{\beta}_{A}^{1}$ implements the policy $\mathbf{p}_{A, C^{L}}^{1}$ and every share $\beta_{A}^{1} \geq \bar{\beta}_{A}^{1}$ implements the policy choice $\mathbf{p}_{A, C^{H}}^{1}$.

Proof. In $t=2$, when $r=n$, any proposer can make a take-it-or-leave-it offer and extract the entire profit. Legislator $g$ makes a take-it-or leave it offer with probability $q$, while the lobby does the same with probability $1-q$, and given that $v_{g g}^{2}\left(\mathbf{p}_{g, C^{H}}^{2}, T_{l g}^{2}\right)=a_{g g}+q \pi-C^{H} \geq$ $a_{g g}=v_{g g}^{2}\left(\mathbf{p}_{g, C^{L}}^{2}, T_{l g}^{2}\right)$ and $v_{l g}^{2}\left(\mathbf{p}_{g, C^{H}}^{2}, T_{l g}^{2}\right)=a_{l g}+(1-q) \pi \geq a_{l g}=v_{l g}^{2}\left(\mathbf{p}_{g, C^{L}}^{2}, T_{l g}^{2}\right)$, the agreement $\mathbf{x}_{n}^{2}=\left(\mathbf{p}_{g, C^{H}}^{2}, q \pi\right)$ is reached. When $r=n-1$, each player is willing to accept a transfer 
that is at least equal to what they could achieve in round $n$ by rejecting in round $n-1$. Hence, again each player would propose $\mathbf{x}_{n-1}^{2}=\left(\mathbf{p}_{g, C^{H}}^{2}, q \pi\right)$, which will be accepted. Moving backward, at $r=1$ the lobby offers $\mathbf{x}_{1}^{2}=\left(\mathbf{p}_{g, C^{H}}^{2}, q \pi\right)$ and $g$ accepts. Moving now to $t=1$, notice that, given $\mathbf{p}_{g, C^{H}}^{2}$, and given the equilibrium voting strategy $\sigma_{m}^{*}=\left[\sigma_{m}^{*}\left(\mathbf{p}_{A, C^{H}}^{1}\right)=\right.$ $\left.0, \sigma_{m}^{*}\left(\mathbf{p}_{A, C^{L}}^{1}\right)=1, \sigma_{m}^{*}\left(\mathbf{p}_{0}^{1}\right)=1\right]$, then $V_{A}\left(\mathbf{p}_{A, C^{H}}^{1},.\right)=a_{A A}+\beta_{A}^{1} \pi-C^{H}+\delta\left(a_{A B}-C^{H}\right) \geq$ $V_{A}\left(\mathbf{p}_{A, C^{L}}^{1},.\right)=a_{A A}+\delta\left[a_{A A}+q \pi-C^{H}\right]$ if and only if $\beta_{A}^{1} \geq \delta q+\frac{C^{H}+\delta\left(a_{A A}-a_{A B}\right)}{\pi}$. Hence, defining $\bar{\beta}_{A}^{1}=\delta q+\frac{C^{H}+\delta\left(a_{A A}-a_{A B}\right)}{\pi}$, we obtain that if $\beta_{A}^{1} \geq \bar{\beta}_{A}^{1}$ is offered, the incumbent $A$ prefers the policy $\mathbf{p}_{A, C^{H}}^{1}$ to the policy $\mathbf{p}_{A, C^{L}}^{1}$.

Note that if $q \pi<C^{H}$ the legislator will never be willing to choose the high cost policy. Hence, electoral accountability is at risk only when $q \pi \geq C^{H}$. For this reason, in the rest of the paper we will assume this restriction to hold. Regarding the first period bargaining, the critical share $\bar{\beta}_{A}^{1}$ depends on the per capita cost $C^{H}$ the legislator pays in the first mandate, the share of profits $q$ he receives in the second mandate if he is reelected, and on the distance between his most preferred policy type and the policy type implemented by legislator $B$ if he goes in power, $\left(a_{A A}-a_{A B}\right)$. In other words, the legislator is willing to choose the high cost project and not be reelected if the share of the rents net of per capita costs received in the first mandate compensates him for the electoral loss consisting in giving up future lobby transfers, and not being able to choose his most preferred policy type.

Turning now to the lobby, since like any other citizen it has preferences for policy types, it will not be indifferent to the change of legislator following the implementation of the high cost policy in the first mandate. The following lemma provides the necessary and sufficient conditions for the lobby to prefer the high cost policy in the first period:

Lemma 2 Let $\bar{\beta}_{l}^{1}=\left(\frac{a_{l A}-a_{l B}}{\pi}\right) \cdot \mathbf{x}^{1}=\left(\mathbf{p}_{A, C}^{1},\left(1-\beta_{l}^{1}\right) \pi\right)$ is an equilibrium offer in period $t=1$ if and only if $\beta_{l}^{1} \geq \delta \bar{\beta}_{l}^{1}=\delta\left(\frac{a_{l A}-a_{l B}}{\pi}\right)$.

Proof. If in $t=1$ the agreement $\mathbf{x}^{1}=\left(\mathbf{p}_{A, C^{H}}^{1},\left(1-\beta_{l}^{1}\right) \pi\right)$ is reached, the lobby obtains $V_{l}\left(\mathbf{p}_{A, C^{H}}^{1}, T_{l g}^{1},.\right)=a_{l A}+\beta_{l}^{1} \pi+\delta\left(a_{l B}+\beta_{l}^{2} \pi\right)$. If no agreement is reached, given that $V_{A}\left(\mathbf{p}_{A, C^{L}}^{1},.\right)>V_{A}\left(\mathbf{p}_{0}^{1},.\right)$ then the legislator unilaterally chooses $\mathbf{p}_{A, C^{L}}^{1}$ and the the lobby obtains $V_{l}\left(\mathbf{p}_{A, C^{L}}^{1},.\right)=a_{l A}+\delta\left(a_{l A}+\beta_{l}^{2} \pi\right)$. Hence, $V_{l}\left(\mathbf{p}_{A, C^{H}}^{1}, T_{l g}^{1},.\right) \geq V_{l}\left(\mathbf{p}_{A, C^{L}}^{1},.\right)$ if and only if $\beta_{l}^{1} \geq \delta\left(\frac{a_{l A}-a_{l B}}{\pi}\right)$.

We are now ready to characterize the policy choice in the first mandate in the following 
Proposition 1 During the first mandate if $\left(a_{A A}-a_{A B}\right) \leq \frac{1}{\delta}\left[(1-\delta q) \pi-C^{H}\right]-\left(a_{l A}-a_{l B}\right)$, policy $\mathbf{p}_{A, C^{H}}^{1}$ is chosen, while if $\left(a_{A A}-a_{A B}\right)>\frac{1}{\delta}\left[(1-\delta q) \pi-C^{H}\right]-\left(a_{l A}-a_{l B}\right)$, policy $\mathbf{p}_{A, C^{L}}^{1}$ is chosen.

Proof. Lemma 2 establishes that $\beta_{l}^{1}=\delta \bar{\beta}_{l}^{1}$ is the minimum share of rents that makes the lobby better off by reaching an agreement $\mathbf{x}^{1}=\left(\mathbf{p}_{A, C^{H}}^{1}, T_{l g}^{1}\right)$. From lemma 1 , we know that $\beta_{A}^{1}=\bar{\beta}_{A}^{1}$ is the minimum payment that makes the legislator (weakly) better off by reaching an agreement $\mathbf{x}^{1}=\left(\mathbf{p}_{A, C^{H}}^{1}, T_{l g}^{1}\right)$. Since the lobby will pay the minimum the legislator is willing to accept, then $\beta_{A}^{1}=\bar{\beta}_{A}^{1}$. Hence, all we need to show is that the lobby will obtain at least a share $\beta_{l}^{1}=\delta \bar{\beta}_{l}^{1}$ after it has paid $\bar{\beta}_{A}^{1}$ or, in other words, $\left(1-\bar{\beta}_{A}^{1}\right) \geq \delta \bar{\beta}_{l}^{1}$, which is true if and only if $\left(a_{A A}-a_{A B}\right) \leq \frac{1}{\delta}\left[(1-\delta q) \pi-C^{H}\right]-\left(a_{l A}-a_{l B}\right)$.

The condition $\left(a_{A A}-a_{A B}\right) \leq \frac{1}{\delta}\left[(1-\delta q) \pi-C^{H}\right]-\left(a_{l A}-a_{l B}\right)$ is equivalent to $\left(\bar{\beta}_{A}^{1}+\delta \bar{\beta}_{l}^{1}\right) \leq 1$ and requires the feasibility of the minimum shares inducing the legislator and the lobby to agree on $\mathbf{p}_{A, C^{H}}^{1}$. The shares depend on the legislator preferences for the project type, and on the bargaining power of the players. It is straightforward to verify that if the legislator has the power to make a take-it-or-leave it offer, i.e. if $q=1$, and the future is not discounted $(\delta=1)$ the minimum share inducing the incumbent to choose the high cost project is not feasible. Therefore, when the legislator has all the bargaining power, he will be accountable to voters. This result is summarized in

Corollary 1 Suppose that $\delta=1$. When the legislator makes a take-it-or-leave-it offer, the policy $\mathbf{p}_{A, C^{L}}^{1}$ is implemented.

Proof. If the legislator has the power to make a take-it-or-leave-it offer and $\delta=1$, then he requires $\bar{\beta}_{A}^{1}=1+\frac{C^{H}+\delta\left(a_{A A}-a_{A B}\right)}{\pi}>1$, which is not feasible.

The opposite case, in which the lobby can make a take-it-or-leave-it offer $(q=0)$, represents the worst case for accountability as the minimum share implementing the high cost policy reaches the lowest value when $q=0$. Note also that the polarization of the political race has a positive effect on accountability. In fact, if the race is very polarized the difference $\left(a_{A A}-a_{A B}\right)$ is large and as a result the feasibility of the minimum share implementing $\mathbf{p}_{A, C^{H}}^{1}$ becomes less likely. 


\section{Bicameralism}

In this section we analyze the impact of bicameralism on electoral accountability. In particular, we explore the effect of alternative institutional rules (i.e. bargaining protocols) regulating the two legislative bodies. Using a bargaining game of alternating offers to analyze this problem has several advantages. First, we can explicitly model the different steps of a sequential legislative process where, at each stage, legislators are allowed to take different actions, like vetoing or amending a proposal previously approved. Second, we are able to acquire some important insights on the relationship between the time structure of the legislative process and the bargaining power of legislators, which turns out to be crucial for electoral accountability. In particular, as the bargaining power of players varies with the configuration of the sequential decision making, then a given number of legislators deciding sequentially does not, in general, deliver the same policy outcome of an identical number of players deciding simultaneously. The consequences of the sequentiality are not trivial. For example, differently from Diermeier and Myerson (1999), in an alternating offer setting there is no perfect equivalence between super-majority rules and approval with sequential veto players. Similarly, a single large chamber made up by the same number of legislators of two chambers will not produce the same outcome as a bicameral system.

How does bicameralism affect the lobbies' ability of buying legislators? Intuitively, introducing multiple legislators makes lobbying more costly, since more decision makers need to be compensated for the implementation of an unpopular policy. At the same time, the creation of additional steps in the legislative process is likely to increase the time span needed for the policy to be adopted, making it potentially difficult to deliberate before the end of the mandate. As a result, a somewhat counter-intuitive consequence of having multiple chambers is that their ability to credibly threaten the rejection of a lobby's proposal to make counteroffers might be considerably reduced because. Hence, a complex legislative structure, besides wasting hours of legislators' time in multiple deliberative sessions, can also increase the ability of the pressure group to influence the decision making process, and make the accountability problem more severe. In what follows we will show how these forces play out under two different institutional arrangements commonly adopted in democracies, i.e. a closed rule and an open rule system. In the former, after the first body has proposed a policy, the other chamber only enjoys veto power. In the latter, all chambers are symmetric 
in the sense of being able to introduce amendments to the original proposal. We will carry out the analysis in a general environment with multiple bodies, of which a bicameral system represents a particular case. This more general set-up is useful to obtain a characterization that can be used to analyze the effect of constitutional arrangements introducing additional veto players - besides the two chambers - in the legislative process. Hence, while this paper focusses on bicameralism, the general theoretical framework with multiple veto players can find a variety of alternative applications. For instance, it can be used to understand the role of presidential veto power or it can be employed to evaluate provisions like the "emergency brake" rule contained in the EU constitution draft. ${ }^{17}$

Before proceeding we need to adapt our notation to accommodate the more complex structure of the game. To that end, suppose that the legislative process involves the sequential approval of $D>1$ chambers denoted by $g_{d}$ with $d=1, \ldots, D$. In each mandate $t$ the chamber $g_{1}$ initiates the process, and lobby $l$ starts the bargaining by making a first offer. If an offer is rejected, the game goes to the next round, where the chamber can make a proposal with probability $q$ and the lobby can make a proposal with probability $1-q$. Let $\mathbf{x}_{g_{1}}^{t}=\left(\mathbf{p}_{g_{1}}^{t}, T_{l g_{1}}^{t}\right)$ be a proposal upon which an agreement has been reached by the lobby and the first chamber, where $\mathbf{p}_{g_{1}}^{t} \in \mathbf{P}^{t}$. Once the two parties have reached an agreement, the legislation passes to the next chamber $g_{2}$, with whom the lobby starts a new bargaining game making a proposal that $g_{2}$ can accept or reject. If the bargaining moves to a subsequent round, the legislative assembly and the lobby would again make offers respectively with probability $q$ and $1-q$. In case of disagreement between the lobby and a chamber, the legislative body can always unilaterally choose his most preferred policy and then the legislation moves again to the following chamber, with which the lobby can start bargaining. However, the policy that each chamber can pass (and the agreement that the lobby can reach with each legislative body) crucially depends on the allocation of legislative powers. The first chamber that has proposal power can choose any policy $\mathbf{p}_{g_{1}}^{t} \in \mathbf{P}^{t}$. As for the subsequent chambers $g_{d}$, $d>1$, when they only have veto power, the feasible policy set available to legislators $d>1$ is $\mathbf{p}_{g_{1}}^{t}$, since they can only decide whether to ratify the policy chosen by the first chamber or veto it. If they instead have amendment rights, the set of feasible policies coincides with $\mathbf{P}^{t}$.

\footnotetext{
${ }^{17}$ This rule allows a member country, that has been outvoted on a proposal in Parliament, to ask for a new vote in the Council. This is equivalent to a system where the first body (Parliament) has proposal power and the second (Council) has final decision power.
} 
Let $\beta_{g_{d}}^{t}$ be the share of the rents paid to legislator $g_{d}$ in period $t$, so that $T_{l g_{d}}^{t}=\beta_{g_{d}}^{t} \pi$ and let $g_{d^{\prime}}$ be a generic legislator, where $d^{\prime}>1$. The lobby's residual profit after an agreement $\mathbf{x}_{g_{d^{\prime}}}^{t}$ has been reached with legislator $d^{\prime}$ are then given by $\pi_{g_{d^{\prime}}}^{t}=\pi\left(1-\sum_{d=1}^{d^{\prime}} \beta_{g_{d}}^{t}\right)$ and the set of feasible agreements between $g_{d^{\prime}+1}$ and $l$ is given by $\mathbf{X}_{g_{d^{\prime}+1}}^{t}=\left\{\left(\mathbf{p}_{g_{1}}^{t}, T_{l g_{d^{\prime}+1}}^{t}\right): \pi_{g_{d^{\prime}}}^{t}-T_{l g_{d^{\prime}+1}}^{t} \geq 0\right\}$ under closed rule and $\mathbf{X}_{g_{d^{\prime}+1}}^{t}=\left\{\left(\mathbf{p}_{g}^{t}, T_{l g_{d^{\prime}+1}}^{t}\right): \pi_{g_{d^{\prime}}}^{t}-T_{l g_{d^{\prime}+1}}^{t} \geq 0\right\}$ under open rule. Figure 2 illustrates the structure of the game under open rule. Importantly, for a policy to be implemented in a multi-chamber setting, some type of deliberation by each chamber is required, i.e. when there are $D$ legislators at least $n=D$ rounds of negotiations are necessary to pass a proposal. Note that if $n=D$, then multiple legislators operate under binding time constraints because, if one of them fails to deliberate during the first round of negotiation, the legislative process cannot be completed. When this happens, a default policy, different from the most preferred one, will be implemented. For simplicity, and without loss of generality, we assume that the default is the no policy option $\mathbf{p}_{0} \cdot{ }^{18}$

The one period payoff to the various agents are analogous to those reported in equations 1 - 4, just replacing equations 3 and 4 with

$$
\begin{gathered}
v_{l g}^{t}\left(\mathbf{p}_{g, C}^{t}, T_{l g_{1}}, \ldots, T_{l_{g_{D}}}\right)=a_{l g}+\left(1-\sum_{d=1}^{D} \beta_{g_{d}}^{t}\right) \pi \\
v_{g_{d} g}^{t}\left(\mathbf{p}_{g, C}^{t}, T_{l g_{1}}, \ldots, T_{l_{g_{D}}}\right)=a_{g g}+\beta_{g_{d}}^{t} \pi-C
\end{gathered}
$$

For simplicity, we rule out the possibility of divided government in our model, assuming that all legislators belong to the same party. ${ }^{19}$ As a result, a voting strategy for the median voter $m$ is a mapping $\sigma_{m}: \mathbf{P}^{1} \rightarrow\{0,1\}$ where $\sigma_{m}=1$ indicates that all the legislators $\{1, \ldots, D\}$ belonging to party A will be reelected, while $\sigma_{m}=0$ means instead that the median voter will cast his ballot in favor of party B. Then $V_{k}$, the inter-temporal utility of

\footnotetext{
${ }^{18}$ Indeed, in the approval of the US states budgets, if the two chambers fail to reach a deliberation by the official deadline, most states operate under legal provisions according to which money cannot be paid from the state treasury without an appropriation. This implies a complete government shut down if a budget has not been not enacted. For more details on late budget procedures see Eckl (1998).

${ }^{19}$ Although in most bicameral systems the two chambers have the same type of majority, divided chambers are not uncommon for example in the US Congress. A companion paper, Testa (2003), shows how divided government decreases electoral accountability.
} 


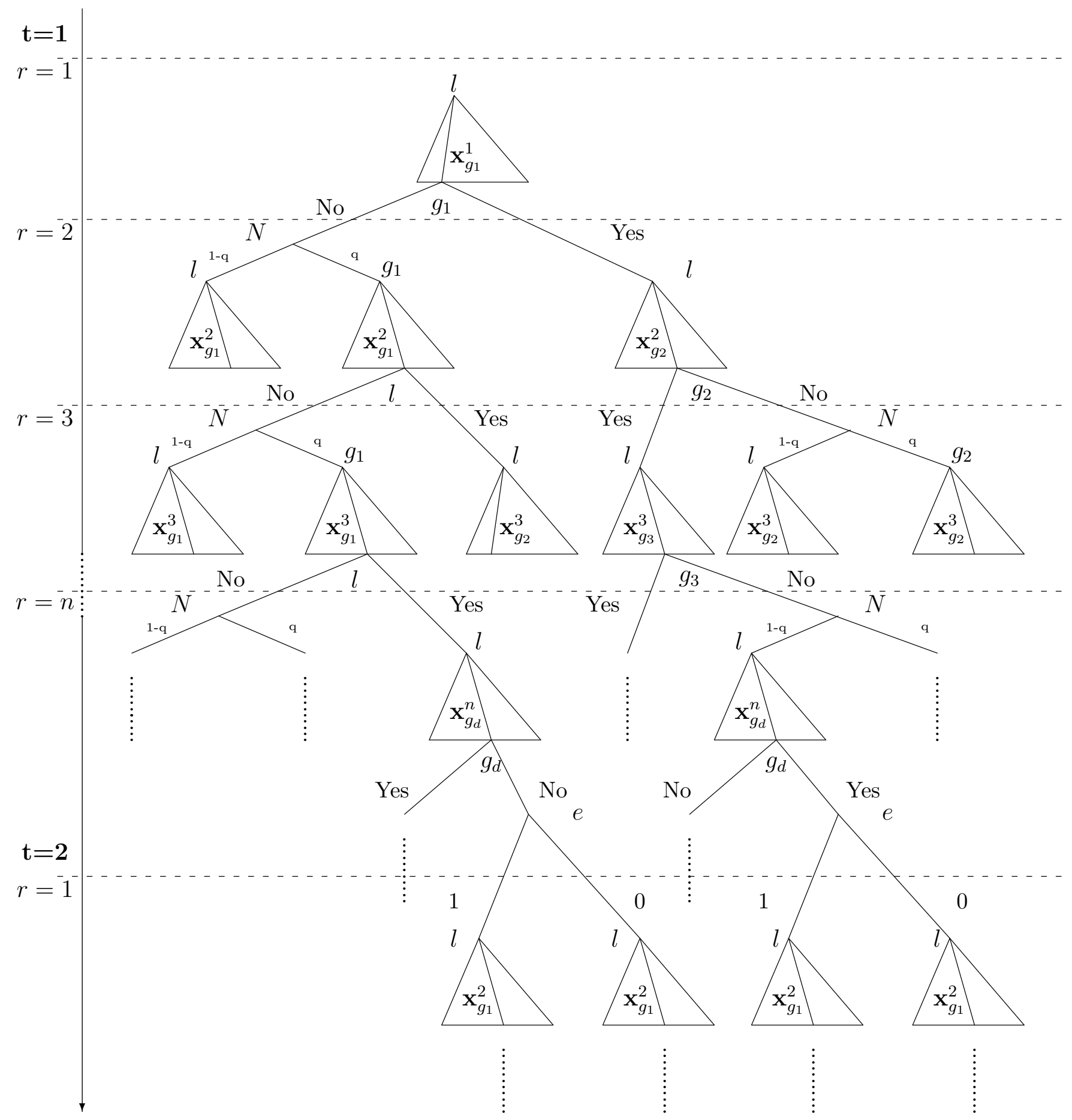

Figure 2: Open rule Multi-cameralism 
individual $k, k \in\left\{g_{d}=A, e, l\right\}$ can be defined as follows:

$$
\begin{aligned}
V_{g_{d}} & =v_{g_{d} A}^{1}+\delta\left[\sigma_{m} v_{g_{d} A}^{2}+\left(1-\sigma_{m}\right) v_{e B}^{2}\right] \\
V_{m} & =v_{m A}^{1}+\delta\left[\sigma_{m} v_{m A}^{2}+\left(1-\sigma_{m}\right) v_{m B}^{2}\right] \\
V_{l} & =v_{l A}^{1}+\delta\left[\sigma_{m} v_{l A}^{2}+\left(1-\sigma_{m}\right) v_{l B}^{2}\right]
\end{aligned}
$$

We are now ready to introduce the political equilibrium. For the voting game, we can use the previous definition. ${ }^{20}$ Concerning the lobbying, we now have a sequence of bargaining games between $l$ and $g_{d}$ within each mandate $t$. Hence, for subgame perfection to hold, in $t=2$ we must require that the strategies played by $l$ and $g_{d}$ in the game starting in $r$ are subgame perfect given not only any strategy played by $l$ and $g_{d}$ in their future rounds of negotiation, but also given any strategies played by $l$ and successive legislators $g_{d+1}$ in every subsequent bargaining game taking place within the same mandate. In $t=1$, on the other hand, we must take into account not only the strategies played in every future round within that period, but also the voting strategy played by the median voter at the and of the first period and the strategies played in every bargaining game between $l$ and $g_{d}$ in $t=2$. Let $\left(\gamma_{l}^{t, r}, \gamma_{g_{d}}^{t, r}\right)$ be a pair of strategies played by legislator $g_{d}$ and lobby $l$ in the bargaining game beginning in $r$, with $r \geq 1$ and $d \geq 1$ and let $r+s$ with $s \geq 1$ denote all future possible rounds within a mandate $t$. Formally, we require the following :

Definition 3 A strategy pair $\left(\gamma_{l}^{2, r *}, \gamma_{g_{d}}^{2, r *}\right)$ is a subgame perfect equilibrium of the bargaining game starting in round $r$ of mandate $t=2$ between $l$ and $g_{d}$ if the strategy pair it induces in every subgame is a Nash equilibrium of that subgame, given any strategy profile $\left(\gamma_{l}^{2, r+s}, \gamma_{g_{d}}^{2, r+s}\right)$ $\forall r, d$.

Definition 4 A strategy pair $\left(\gamma_{l}^{1, r *}, \gamma_{g_{d}}^{1, r *}\right)$ is a subgame perfect equilibrium of the bargaining game starting in $n$ round $r$ of mandate $t=1$ between $l$ and $g_{d}$ if the strategy pair it induces in every subgame is a Nash equilibrium of that subgame,given any strategy profile $\left(\gamma_{l}^{1, r+s}, \gamma_{g_{d}}^{1, r+s}, \sigma_{m}, \gamma_{l}^{2, r}, \gamma_{g_{d}}^{2, r}\right) \forall r, d$

\footnotetext{
${ }^{20}$ The only difference here is that the median voter chooses a voting strategy maximizing $V_{m}($.$) given a$ more complex strategy profile $\left(\gamma_{l}^{1, r}, \gamma_{g_{d}}^{1, r}, \gamma_{l}^{2, r}, \gamma_{g_{d}}^{2, r}\right)$ of the first and second period bargaining games between $l$ and $g_{d}$.
} 
Definition 5 A political equilibrium is a strategy profile $\left(\gamma_{l}^{1, r *}, \gamma_{g_{d}}^{1, r *}, \sigma_{m}^{*}, \gamma_{l}^{2, r *}, \gamma_{g_{d}}^{2, r *}\right)$ such that:

i) $\left(\gamma_{l}^{2, r *}, \gamma_{g_{d}}^{2, r *}\right)$ is a subgame perfect equilibrium of each second period bargaining game between $l$ and $g_{d}$ beginning in $r$;

ii) $\sigma_{m}^{*}$ is an equilibrium of the voting game;

iii) $\left(\gamma_{l}^{1, r *}, \gamma_{g_{d}}^{1, r *}\right)$ is a subgame perfect equilibrium each first period bargaining game between $l$ and $g_{d}$ beginning in $r$.

\subsection{Closed rule}

We begin our analysis by considering the case where the first legislator has proposal power and the subsequent legislators can only pass or veto previously approved proposals. The profit shares that legislators are able to extract bargaining with the lobby depend in a fundamental way on their ability to credibly threaten the rejection of the lobby's proposal and also on the type of policy decision they can undertake (i.e. whether they can propose a policy or can only approve or veto an existing proposal). Since in a strategic bargaining context the time available to negotiate is crucial for the rejection of proposals to be a credible threat, the length of the legislative process can have an important effect on the bargaining power of legislators. When the time available for lawmaking is limited, so that the rejection of the lobby's proposal will result in the inability to pass a bill, the bargaining power of multiple legislators can be seriously limited, and time constraints are obviously more likely to be binding the higher the number of legislative bodies that need to deliberate in a given time span. As for the legislators' institutional rights, under closed ruled, the first legislator enjoys a substantial advantage that should be reflected in the extraction of a higher profit share than the subsequent ones. These intuitive arguments are formalized in

Lemma 3 The following holds:

i) Suppose that $D=n-k$, with $k \geq 1$. In $t=2$ and $r=1, \mathbf{p}_{g, C^{H}}^{2}$ is chosen and $\beta_{g_{1}}^{2}=q$, while $\beta_{g_{d}}^{2}=0 \forall d>1$. In $t=1$ the minimum profit shares required by each legislator $g_{d}$ to choose $\mathbf{p}_{A, C^{H}}^{1}$ are $\bar{\beta}_{g_{1}}^{1}=\delta q+\frac{C^{H}+\delta\left(a_{A A}-a_{A B}\right)}{\pi}$ and $\bar{\beta}_{g_{d}}^{1}=\frac{\delta\left(a_{A A}-a_{A B}\right)}{\pi}+\frac{C^{H}-a_{A A}}{\pi} \forall d>1$. 
ii) Suppose that $D=n$. In $t=2$ and $r=1, \mathbf{p}_{g, C^{H}}^{2}$ is chosen and $\beta_{g_{1}}^{2}=\frac{C^{H}}{\pi}$, while $\beta_{g_{d}}^{2}=0 \forall d>1$. In $t=1$ the minimum share required to implement $\mathbf{p}_{A, C^{H}}^{1}$ are $\bar{\beta}_{g_{1}}^{1}=$ $\delta \frac{C^{H}}{\pi}+\frac{C^{H}+\delta\left(a_{A A}-a_{A B}\right)}{\pi}$ and $\bar{\beta}_{g_{d}}^{1}=\frac{\delta\left(a_{A A}-a_{A B}\right)}{\pi}+\frac{C^{H}-a_{A A}}{\pi} \forall d>1$.

Proof. See Appendix.

The previous lemma illustrates two important points. First, it shows how the distribution of proposal and veto powers has an impact on the cost of buying each chamber. Second, it establishes how the number of negotiation rounds, by affecting the ability of legislators to credibly threaten the rejection of the lobby's proposal, influences the cost of lobbying. As we can see from the second period minimum profit shares obtained by the various players, the first legislator can extract a positive share, provided that the number of rounds is sufficiently large for him to make at least one counter-offer with probability $q$. On the other hand, the subsequent legislators, enjoying only veto power, cannot extract any positive lobby's payment since vetoing a proposal gives them a lower pay-off than approving any proposal passed by the first legislator. The profit shares in the second mandate have in turn an impact on their first period counterparts. Similarly to the unicameral case, legislators require a minimum transfer that should compensate them for the "policy loss" and "profit loss" they would incur in the second period by pleasing the lobby rather than the electorate. As a consequence, legislators enjoying only veto power demand a minimum share that only compensates them for the potential "policy loss", since in the second period they cannot obtain any profit. On the other hand, the first legislator requires compensation for both the future "policy loss" and "profit loss". Clearly, the second period profit loss of the first chamber depends on its bargaining power, which in turn depends on the time available to negotiate. In particular, when time constraints are not binding $(n>D=n-k)$, the first chamber can credibly threaten to reject the first lobby offer since the time horizon allows it to make at least a counter-offer with probability $q$. On the other hand, with binding time constraints $(D=n)$ the first legislator looses the right to make counter-offers, because a rejection of the first lobby's proposal will result in a failure to approve any legislation by the end of the mandate. ${ }^{21}$ This situation might well occur when official deadlines to pass a legislation are in place, like in the case of the annual budget process in the US federal states. ${ }^{22}$

\footnotetext{
${ }^{21}$ In other words, when the number of negotiation rounds is sufficiently big $(D=n-k)$, the lobby looses her first mover advantage, while this is not the case for $D=n$.

${ }^{22}$ For an overview of budgetary deadlines and procedures in the US states see NASBO (2002).
} 
Note that, when the time constraints are not binding (i.e. $D<n$ ), the first legislators requires a minimum share coinciding with the share demanded in a unicameral system (i.e. $\left.\bar{\beta}_{g 1}^{1}=\bar{\beta}_{A}^{1}\right)$. Given that all subsequent legislators require a non-negative share, ${ }^{23}$ then the total share of rents received by policymakers in the multi-chamber context cannot be smaller than the share received by a legislator in a unicameral system, i.e. $\sum_{d=1}^{D} \bar{\beta}_{g_{d}}^{1} \geq \bar{\beta}_{A}^{1}$. Hence, in this case, the cost of lobbying increases monotonically with the number of legislators. ${ }^{24}$ On the other hand, under binding time constraints $(D=n)$, the loss of bargaining power for the first legislator (implying a smaller minimum share than a legislator operating under unicameralism) constitutes an important drawback of a multi-chamber system, which can work against the interest of the electorate. In this case, we can establish the following non monotonicity result:

Lemma 4 Suppose that $D=n$. If $(D-1)\left[\delta\left(a_{A A}-a_{A B}\right)+C^{H}-a_{A A}\right]<\delta\left(q \pi-C^{H}\right)$, then the share of rents paid to a single legislator is bigger than the sum of the shares paid to $D$ legislators, while the opposite holds if $(D-1)\left[\delta\left(a_{A A}-a_{A B}\right)+C^{H}-a_{A A}\right] \geq \delta\left(q \pi-C^{H}\right)$.

Proof. When $D=n$, since $\bar{\beta}_{A}^{1}=\delta q+\frac{C^{H}+\delta\left(a_{A A}-a_{A B}\right)}{\pi}, \bar{\beta}_{g_{1}}^{1}=\delta \frac{C^{H}}{\pi}+\frac{C^{H}+\delta\left(a_{A A}-a_{A B}\right)}{\pi}, \bar{\beta}_{g_{d}}^{1}=$ $\frac{\delta\left(a_{A A}-a_{A B}\right)}{\pi}+\frac{C^{H}-a_{A A}}{\pi} \quad \forall d>1$ then $\bar{\beta}_{g_{1}}^{1}+(D-1) \bar{\beta}_{g_{d}}^{1} \leq \bar{\beta}_{A}^{1} \Leftrightarrow(D-1)\left[\delta\left(a_{A A}-a_{A B}\right)+C^{H}-a_{A A}\right] \leq$ $\delta\left(q \pi-C^{H}\right)$.

Intuitively, the total transfer required by legislators to compensate the "policy component" of their electoral loss (ideological loss and high per capita cost) increases as more lawmakers need to be payed off. ${ }^{25}$ On the other hand, the compensation for the loss of future lobby transfers required by the first legislator decreases because of its inability to credibly reject a lobby proposal given the binding time constraints. Hence, only when the increase in the policy component of the electoral loss more than compensates the decrease

\footnotetext{
${ }^{23}$ The minimum share required by $d>1$ legislators is $\bar{\beta}_{g_{d}}^{1}=\frac{\delta\left(a_{A A}-a_{A B}\right)}{\pi}+\frac{C^{H}-a_{A A}}{\pi}$, where $\bar{\beta}_{g_{d}}^{1}>0$ when $\frac{\delta\left(a_{A A}-a_{A B}\right)}{\pi}+\frac{C^{H}-a_{A A}}{\pi} \geq 0$ and $\bar{\beta}_{g_{d}}^{1}=0$ when $\frac{\delta\left(a_{A A}-a_{A B}\right)}{\pi}+\frac{C^{H}-a_{A A}}{\pi}<0$.

${ }^{24}$ We focus on the cost of lobbying deriving from the electoral loss of multiple legislators because we are mainly interested in electoral incentives. However, it should be clear that having multiple chambers deciding sequentially rather than simultaneously can have a substantial impact on the lobby's ability to bribe the legislator whenever lobbying is a costly, time consuming activity or the rents associated to from an agreement decrease with time. Hence, our results on the positive effect of bicameralism on accountability hold a fortiori if we introduce either a cost of lobbying or a profit that are time dependent.

${ }^{25}$ The electoral loss is equal to $\left[\delta\left(a_{A A}-a_{A B}\right)+C^{H}\right]$ for the legislator with proposal power and $\delta\left[\left(a_{A A}-\right.\right.$ $\left.\left.a_{A B}\right)+C^{H}\right]+\frac{C^{H}-a_{A A}}{\pi}$ for the legislators with only veto power.
} 
in bargaining power, the cost of lobbying increases with the number of legislator making multiple chambers potentially more accountable to voters. The non monotonic relationship between accountability and the number of legislators pointed out in lemma 4 contrasts with the findings of Diermeier and Myerson (1999), where the so called external hurdle factor ${ }^{26}$ increases monotonically with the number of decision makers. Thus, our result points out a drawback of increasing the number of legislative bodies and provides a potential rationale for current reform proposals aiming for shorter and simpler legislative procedures in US federal states. However, to obtain some interesting predictions on reforms and accountability, we first need to establish some comparative results on the policy choices under alternative legislative procedures.

To keep the characterization of the policy choice as simple as possible, from now on we will assume that the lobby always prefers the high cost to the low cost policy. ${ }^{27}$ Notice also that if $\frac{\delta\left(a_{A A}-a_{A B}\right)}{\pi}+\frac{C^{H}-a_{A A}}{\pi}<0$, an increase in the number of legislators does not affect accountability since they require a zero minimum profit share. For this reason, in the remainder of the paper, we will assume the following:

Assumption $1 \frac{\delta\left(a_{A A}-a_{A B}\right)}{\pi}+\frac{C^{H}-a_{A A}}{\pi}>0$.

Let $\bar{\beta}_{A, n}^{1}$ be the sum of the minimum rent shares $D$ legislators are willing to accept to implement $\mathbf{p}_{A, C^{H}}^{1}$ when $D=n$, and let $\bar{\beta}_{A, n-k}^{1}$ be the sum of the minimum shares required when $D=n-k, k \geq 1$. The next result fully characterizes the conditions under which legislators choosing the low cost policy are accountable to voters and choosing the high cost are not:

Theorem 1 The following holds:

i) Assume that $D=n-k$. If $\bar{\beta}_{A}^{1}<\bar{\beta}_{A, n-k}^{1}<1$, then legislators are never accountable, whereas if $\bar{\beta}_{A, n-k}^{1}>\bar{\beta}_{A}^{1}>1$ then legislators are always accountable. If instead $\bar{\beta}_{A}^{1}<1<$ $\bar{\beta}_{A, n-k}^{1}$ then legislators are accountable under multicameral arrangements only.

ii) Assume that $D=n$. If $\bar{\beta}_{A}^{1}<\bar{\beta}_{A, n}^{1}<1$ then legislators are never accountable, whereas for $\bar{\beta}_{A}^{1}>\bar{\beta}_{A, n}^{1}>1$ or $\bar{\beta}_{A, n}^{1}>\bar{\beta}_{A}^{1}>1$, they are always accountable. Finally, if $\bar{\beta}_{A, n}^{1}<$

\footnotetext{
${ }^{26}$ Expressing the difficulty of buying legislators.

${ }^{27}$ This implies that the condition $\beta_{l}^{1} \geq \delta \bar{\beta}_{l}^{1}$ derived in lemma 2 is always satisfied.
} 
$1<\bar{\beta}_{A}^{1}$ then legislators are accountable under a unicameral arrangement only, while if $\bar{\beta}_{A}^{1}<1<\bar{\beta}_{A, n}^{1}$ they are accountable only under multicameral ones.

Proof. See Appendix.

From the theorem we obtain a number of important insights on the relative effectiveness of unicameralism and multi-cameralism with respect to electoral accountability. Interestingly, while under several parameter's configurations the two systems deliver the same policy outcomes, there are two cases where one type of legislative arrangement can be clearly ranked above the other in terms of electoral accountability. When the minimum rent share legislators are willing to accept under unicameralism is feasible and inferior to the non-feasible share under bicameralism $\left(\bar{\beta}_{A}^{1}<1<\bar{\beta}_{A, n-k}^{1}\right)$, then we have the traditional Madisonian argument in favor of bicameralism, i.e. that while one chamber can be easily corrupted, the cost of buying two chambers is so high that accountability can be achieved. However, this outcome is possible only insofar as multiple legislators retain bargaining power. Hence, when binding time constraints do not to allow chambers to extract rents by credibly threatening the rejection of a lobby proposal, then bicameralism will in fact have an opposite effect on accountability. By increasing the time necessary to pass legislation, a bicameral system can decrease the minimum rent shares legislators are willing to accept up to the point where multiple chambers can be bought by the lobby while a single one remains accountable to the electorate $\left(\bar{\beta}_{A, n}^{1}<1<\bar{\beta}_{A}^{1}\right)$. Hence, our model delivers an important caveat on adding multiple legislative steps in the law making process, since long and complex legislative procedures may ultimately weaken legislators and hurt voters. This result provides an important rationale for the unicameral proposals currently being discussed in several US states advocating the abolition of time consuming legislative procedures. While those proposals just point out that abolishing redundant legislative sessions will save hours of wasted legislators' time, our analysis uncovers that there is a more profound meaning to the "value of time" in a legislative process since an extended time horizon for lawmaking can increase the bargaining power of parliamentary bodies as well as their electoral accountability.

\subsection{Open rule}

When amendment rights are ruled out, the power to choose the content of the new legislation is given entirely to the chamber initiating the process, while the following legislators can 
only decide whether to approve or not the initial proposal. If amendment rights are instead introduced, the subsequent legislators can actually modify the original policy. Since the first chamber will anticipate this possibility, the existence of amendment rights is likely to have an important effect, and to analyze it we concentrate for simplicity on the case where all $D$ legislators have the possibility to make at least one counter-offer (i.e. $n \geq 2 D$ ). We consider both the case of unrestricted amendment rights, i.e. the situation in which the policy passed by the previous chamber can unilaterally be modified by the subsequent legislators, and the situation in which the amendments introduced require the approval of all legislators (restricted amendment rights). In both cases, chambers $d>1$ can only amend a legislative proposal passed by the first chamber, or in other words, they do not have the power to initiate the legislative process. ${ }^{28}$ If no legislation is passed in the first chamber, then the mandate ends with no policy being implemented.

The following lemma characterizes the first and second period minimum profit shares required to implement the high cost policy under restricted and unrestricted amendment rights. Let $\bar{\beta}_{g_{d}}^{1}=R \delta q(1-q)^{d-1}+g(d, R) \delta q+\frac{C^{H}+\delta\left(a_{A A}-a_{A B}\right)}{\pi}$ be the minimum payment that each legislator $g_{d}$ is willing to accept in order to implement $\mathbf{p}_{A, C^{H}}^{1}$ under restricted $(R=1)$ or unrestricted $(R=0)$ amendment rights, where $g(d, 1)=0 \forall d, g(d, 0)=0 \forall d<D$ and $g(d, 0)=1$ if $d=D$. The following holds:

Lemma 5 Suppose that $q(1-q)^{D-1} \geq \frac{C^{H}}{\pi}$. In period $t=2$ during the first round of negotiations the policy $\mathbf{p}_{A, C^{H}}^{2}$ is chosen and each legislator obtains $\beta_{g_{d}}^{2}=R q(1-q)^{d-1}+$ $g(d, R) \delta q$ where $d=1, \ldots, D$. In period $t=1$ the minimum share required by each legislator $g_{d} \quad$ to choose policy $\mathbf{p}_{A, C^{H}}^{1}$ is $\bar{\beta}_{g_{d}}^{1}=R \delta q(1-q)^{d-1}+g(d, R) \delta q+\frac{C^{H}+\delta\left(a_{A A}-a_{A B}\right)}{\pi} \forall d \geq 1$.

Proof. See Appendix.

It is important to remark that under restricted amendment rights $(R=1)$, every chamber requires in the second period a positive share of the lobby profit, since they all enjoy some bargaining power as they have the same amendment rights. These findings are very different from the closed rule system, where in the second mandate the first legislator only, enjoying proposal power, can require a positive rent. ${ }^{29}$ On the other hand, with unrestricted

\footnotetext{
${ }^{28}$ This type of arrangement is very common. For instance, in the US only the House of Representatives can initiate budget legislation.

${ }^{29}$ As we can see, under restricted amendment rights, the first legislator receives $\beta_{g_{1}}^{2}=q$ as in the closed
} 
amendment rights $(R=0)$, the sum of the shares paid to the legislators is identical to the closed rule case, but the power of the legislators is reversed. In fact, the last legislator, rather than the first, is now in the position to extract a positive profit share in the second period.

Given these differences due to alternative allocations of proposal powers, we can establish some interesting comparative results between open and closed rules systems. Since in the second term the policy $\mathbf{p}_{g, C^{H}}^{2}$ is always carried out, we focus on the first period policy choice. The next theorem summarizes our main findings:

\section{Theorem 2 The following holds}

i) Suppose that amendment rights are restricted $(R=1)$. If the low cost policy is chosen under closed rule then the low cost policy is chosen also under open rule, while the reverse is not true.

ii) Suppose that amendment rights are unrestricted $(R=0)$. If the low cost is chosen under open rule than the same policy is also chosen under closed rule, while the reverse is not true. In particular, if $\sum_{d=1}^{D-1} \bar{\beta}_{g_{d}}^{1}>1$ but $\bar{\beta}_{g_{D}}^{1}=\bar{\beta}_{A}^{1}<1$, then the low cost policy is chosen under closed rule, while the status quo policy $\left(\mathbf{p}_{0}^{1}\right)$ is implemented under open rule.

Proof. See Appendix.

The intuition for the first part of the theorem is quite straightforward. When amendment rights are restricted, the total share to be paid to legislators to obtain the high cost policy is always higher than under closed rule (lemma 5). Hence, if the total share under closed rule is feasible, while the total share under open rule is not, legislators who are not accountable under closed rule become accountable under open rule. However, if amendment rights are unrestricted, then the implications in terms of accountability are different. Interestingly, when the lobby can afford to pay only the most powerful individual legislator, under open rule the status quo $\left(\mathbf{p}_{0}^{1}\right)$ is implemented, while in the closed rule setting the low cost policy would be chosen. In other words, when the final legislator can unilaterally change a previously

rule case, but all subsequent legislators $d>1$ receive $\beta_{g_{d}}^{2}=q(1-q)^{d-1}$, while under closed rule $\beta_{g_{d}}^{2}=0$ for all $d>1$ (see lemma 3). One might wonder if these results would continue to hold in a different model, where the lobby can use strategic delays to reduce the legislators' ability of making counter-offers. As long as players are sufficiently impatient, our results still carry through, i.e. the lobby in the second mandate has to pay all legislators to obtain the low cost policy. 
approved proposal, a status quo bias arises because the first legislator prefers not approving a policy proposal rather than passing a low cost policy that can be amended to high cost by the last bribed decision maker. The problem of the potential status quo bias associated with multiple legislators has been stressed by other authors. ${ }^{30}$ However, differently from the existing literature, our analysis emphasizes that this risk is real only when subsequent legislators are given more power than the first one, as in the case of unrestricted amendment rights. On the other hand, if amendment rights are restricted, then situations of legislative impasse can be avoided and an open rule bicameralism becomes an effective instrument to improve accountability. This factor seems to have been taken into account in the design of many legislative bodies around the world, in which amendments implemented by the second chamber need to be approved by the first chamber as well. ${ }^{31}$

To complete our discussion of bicameralism and accountability, we would like to briefly consider another example in which bicameralism turns out to be neutral. Suppose that for a given economic environment, the policy preferred by the lobby is the status quo, while the voters prefer instead a different policy. In this case, with a bicameral system, voters need the approval of two legislative bodies to see the implementation of their preferred policy, while the lobby will be satisfied just by the negative decision of one chamber. It is then clear that the existence of a second legislator does not have any effect since the cost of lobbying does not change compared to the one chamber case. In other words, policy choices implemented by negative decisions are "cheaper" to buy than policy choices requiring a positive decision. Therefore, if the lobby supports the status quo, increasing the number of legislators does not help solving the accountability problem.

\section{Conclusions}

In this paper we have developed a theoretical framework to analyze the effects of bicameralism on lawmakers' accountability to the public. In particular, inspired by the current

\footnotetext{
${ }^{30}$ See for instance Tsebelis and Money (1997).

${ }^{31}$ In most countries, this means that the text of a bill needs to be approved in the same form by both legislative bodies. Hence, in case of disagreement, the bill shuttles between the two chambers until an agreement is reached. However, in extreme cases of complete parliamentary deadlock, other mechanisms have been devised. For instance, in the US a conference committee can be called where delegates from each chamber meet to find a compromise. For more details see Tsebelis and Money (1997).
} 
debate on constitutional reform in several US states, we have considered how the number of chambers in a parliament and the allocation of powers among them can discipline elected representatives and limit the ability of pressure groups to buy influence. To that end, we have built a model in which legislators interact with a lobby group through a bargaining process, and with voters by means of elections.

Our analysis delivers two important messages that should be taken into account in designing reforms of the legislative process. First, the greater complexity induced by an additional chamber may come with an undesirable effect, i.e. the loss of bargaining power for the elected body vis-à-vis the lobby. Additional steps increase the time necessary to pass legislation. Hence, when the chambers have limited time to deliberate, legislators might not be able to credibly threaten the rejection of a lobby's proposal to extract rents. When this happens, bicameralism might well have a detrimental effect on accountability. On the other hand, if time constraints are not binding, a larger number of legislative bodies may increase the cost of lobbying and, therefore, enhance electoral accountability. If this is the case, the second important message of our analysis is that the effectiveness of a bicameral system crucially depends on the rules governing the two elected bodies, and in particular the allocation of the decision power between the chambers. For accountability purposes, the best incentives are provided whenever two legislative bodies share equal decision powers (i.e. restricted amendment rights). Having instead unrestricted amendment rights can result in a status quo bias, whereby no new legislation is passed.

The debate on the effectiveness of bicameral as opposed to unicameral arrangements is not unique to US state legislatures. National states such as Germany and Italy have been considering reforms of their parliamentary bodies to reduce the power of the senate, whereas the UK proposal to render the Lords an elected body with substantive legislative powers pushed in the opposite direction. The role of the council of states in the European Union and its potential to act as a second chamber, in addition to the existing parliament, is also one of the many controversial issues surrounding the drafting of the EU constitution. How far can we go in applying our analysis of bicameralism to these alternative contexts? Differently from sub-national state legislatures, national and federal legislative bodies, besides the yearly budget approval, often deal with matters of constitutional relevance or important reforms of general interest, for which time constraints are typically not binding. In this case a more complex process does not translate in more lobby capture, while the scrutiny by two bodies 
can provide better expertise and more careful deliberation. Thus, if bicameralism is to be advantageous, its role could be confined to matters of general interest for which timely deliberations are not a priority. More research is necessary though to formally establish how different tasks should be allocated to decision-makers.

\section{Appendix}

\subsection{Equilibrium Voting Strategy}

Result 1 The strategy $\sigma_{m}^{*}=\left[\sigma_{m}^{*}\left(\mathbf{p}_{A, C^{H}}^{1}\right)=0, \sigma_{m}^{*}\left(\mathbf{p}_{A, C^{L}}^{1}\right)=1, \sigma_{m}^{*}\left(\mathbf{p}_{0}^{1}\right)=1\right]$ is an equilibrium voting strategy, i.e. $V_{m}\left(., \sigma_{m}^{*}\right) \geq V_{m}\left(., \sigma_{m}\right) \forall \sigma_{m} \neq \sigma_{m}^{*}$.

Proof. Since the voting decision depends only on the policy outcome, the same argument applies for a single as well as for multiple legislators. This proof is therefore carried out for the more general situation in which we have $D$ legislators. Notice that in the second period $\mathbf{p}_{A, C^{H}}^{2}$ is chosen under any legislative procedure and given any voting rule. Hence, we conclude that to show whether $V_{m}\left(., \sigma_{m}^{*}\right) \geq V_{m}\left(., \sigma_{m}\right)$, we only need to analyze the first period payoff $v_{m}^{1}\left(\mathbf{p}^{1}, \sigma_{m}\right)$ for all $\sigma_{m}$. Let us start by considering the following alternative strategy

$$
\sigma_{m}^{1}=\left[\sigma_{m}^{1}\left(\mathbf{p}_{A, C^{H}}^{1}\right)=1, \sigma_{m}^{1}\left(\mathbf{p}_{A, C^{L}}^{1}\right)=1, \sigma_{m}^{1}\left(\mathbf{p}_{0}^{1}\right)=1\right]
$$

Under $\sigma_{m}^{1}, \mathbf{p}_{A, C^{H}}^{1}$ is the policy preferred by any legislator receiving $\beta_{g_{d}} \geq 0$, since he can receive lobby transfers and choose his most preferred policy in both periods. On the other hand, under the voting strategy $\sigma_{m}^{*}$ depending on the parameters of the model, either $\mathbf{p}_{A, C^{H}}^{1}$ or $\mathbf{p}_{A, C^{L}}^{1}$ can be implemented. Notice that from propositions $1-6$, when the policy $\mathbf{p}_{A, C^{H}}^{1}$ is chosen then $V_{m}\left(., \sigma_{m}^{1}\right)=V_{m}\left(, \sigma_{m}^{*}\right)$. On the other hand, when the policy $\mathbf{p}_{A, C^{L}}^{1}$ is chosen then $V_{m}\left(., \sigma_{m}^{1}\right)<V_{m}\left(., \sigma_{m}^{*}\right)$. Hence, we conclude that $V_{m}\left(., \sigma_{m}^{1}\right) \leq V_{m}\left(, \sigma_{m}^{*}\right)$ and therefore $\sigma_{m}^{1}$ is not an equilibrium strategy. Consider next the following alternative strategy

$$
\sigma_{m}^{2}=\left[\sigma_{m}^{2}\left(\mathbf{p}_{A, C^{H}}^{1}\right)=0, \sigma_{m}^{2}\left(\mathbf{p}_{A, C^{L}}^{1}\right)=0, \sigma_{m}^{2}\left(\mathbf{p}_{0}^{1}\right)=0\right]
$$

Under the voting rule $\sigma_{m}^{2}$ the incumbent is never reappointed. Therefore, since $\mathbf{p}_{A, C^{H}}^{1}$ generates a higher net profit to be shared, $V_{g_{d}}\left(\mathbf{p}_{A, C^{H}}^{1}\right) \geq V_{g_{d}}\left(\mathbf{p}_{A, C^{L}}^{1}\right) \forall \beta_{g_{d}}^{1} \geq 0$, which implies that $\mathbf{p}_{A, C^{H}}^{1}$ will always be chosen. Hence, as in the previous case, $\sigma_{m}^{2}$ is not an equilibrium voting 
strategy. Consider next

$$
\sigma_{m}^{3}=\left[\sigma_{m}^{3}\left(\mathbf{p}_{A, C^{H}}^{1}\right)=0, \sigma_{m}^{3}\left(\mathbf{p}_{A, C^{L}}^{1}\right)=1, \sigma_{m}^{3}\left(\mathbf{p}_{0}^{1}\right)=0\right]
$$

Note that under this voting strategy a legislator is not re-elected if he chooses the status quo. As $v_{g_{d}}^{1}\left(\mathbf{p}_{A, C^{L}}^{1}\right)>v_{g_{d}}^{1}\left(\mathbf{p}_{0}^{1}\right)$ for all $d$, when legislators do not receive transfers from the lobby, they always prefer to implement $\mathbf{p}_{A, C^{L}}^{1}$, i.e. $\mathbf{p}_{A, C^{L}}^{1}$ is their outside option. Since when offered transfers legislators choose between $\mathbf{p}_{A, C^{H}}^{1}$ and their outside option $\mathbf{p}_{A, C^{L}}^{1}$, the punishment $\sigma_{m}^{3}\left(\mathbf{p}_{0}^{1}\right)=0$ is irrelevant except for the unrestricted amendment rights case, where $\mathbf{p}_{0}^{1}$ can be an outside option. Remember that with unrestricted amendment rights, given $\sigma_{m}^{*}$, we know that if $\delta q+D\left[\frac{C^{H}+\delta\left(a_{A A}-a_{A B}\right)}{\pi}\right]>1$ but $\delta q+\frac{C^{H}+\delta\left(a_{A A}-a_{A B}\right)}{\pi}<1$, then for $\delta \geq \hat{\delta}, V_{g_{1}}\left(\mathbf{p}_{0}^{1}\right)>V_{g_{1}}\left(\mathbf{p}_{g_{1}, C^{L}}^{1}\right)$ and $\mathbf{p}_{0}^{1}$ is chosen to prevent the final implementation of $\mathbf{p}_{g_{D}, C^{H}}^{1}$ However, under $\sigma_{m}^{3}$ because of the punishment $\sigma_{m}^{3}\left(\mathbf{p}_{0}^{1}\right)=0$, for the first legislator the following holds: $V_{g_{1}}\left(\mathbf{p}_{A, C^{L}}^{1}\right)=a_{A A}-C^{H}+\delta\left(a_{A B}-C^{H}\right)>V_{g_{1}}\left(\mathbf{p}_{0}^{1}\right)=\delta\left(a_{A B}-C^{H}\right)$. Hence, the first legislator chooses $\left(\mathbf{p}_{A, C^{L}}^{1}\right)$ and the last legislator amends it passing $\left(\mathbf{p}_{A, C^{H}}^{1}\right)$. Since for the median voter $v_{m}^{1}\left(\mathbf{p}_{A, C^{H}}^{1}\right)<v_{m}^{1}\left(\mathbf{p}_{0}^{1}\right)$ clearly $V_{m}\left(., \sigma_{m}^{3}\right)<V_{m}\left(., \sigma_{m}^{*}\right)$.

Since the previous voting strategies will not be played in equilibrium, then from the preference ordering $v_{m}^{1}\left(\mathbf{p}_{A, C^{H}}^{1}\right)<v^{1}\left(\mathbf{p}_{0}^{1}\right)<v_{m}^{1}\left(\mathbf{p}_{A, C^{L}}^{1}\right)$ the same is true for:

$$
\begin{gathered}
\sigma_{m}^{4}=\left[\sigma_{m}^{4}\left(\mathbf{p}_{A, C^{H}}^{1}\right)=1, \sigma_{m}^{4}\left(\mathbf{p}_{A, C^{L}}^{1}\right)=0, \sigma_{m}^{4}\left(\mathbf{p}_{0}^{1}\right)=1\right] \\
\sigma_{m}^{5}=\left[\sigma_{m}^{5}\left(\mathbf{p}_{A, C^{H}}^{1}\right)=1, \sigma_{m}^{5}\left(\mathbf{p}_{A, C^{L}}^{1}\right)=0, \sigma_{m}^{5}\left(\mathbf{p}_{0}^{1}\right)=0\right] \\
\sigma_{m}^{6}=\left[\sigma_{m}^{6}\left(\mathbf{p}_{A, C^{H}}^{1}\right)=0, \sigma_{m}^{6}\left(\mathbf{p}_{A, C^{L}}^{1}\right)=0, \sigma_{m}^{6}\left(\mathbf{p}_{0}^{1}\right)=1\right] \\
\sigma_{m}^{7}=\left[\sigma_{m}^{7}\left(\mathbf{p}_{A, C^{H}}^{1}\right)=1, \sigma_{m}^{7}\left(\mathbf{p}_{A, C^{L}}^{1}\right)=1, \sigma_{m}^{7}\left(\mathbf{p}_{0}^{1}\right)=0\right]
\end{gathered}
$$

\subsection{Proof of Lemma 3}

Proof. In $t=2$ the following holds. For $D=n-k$, the first legislator $g_{d}$ has the power to make at least one counter-offer with probability $q$. In the absence of lobby transfers $\left(T_{l g_{d}}^{2}=0\right)$ given that $v_{g_{d} g}^{2}\left(\mathbf{p}_{g, C^{L}}^{2}\right)>v_{g_{d} g}^{2}\left(\mathbf{p}_{g, C^{H}}^{2}\right)>v_{g_{d} g}^{2}\left(\mathbf{p}_{0}^{2}\right)$, the first legislator $g_{1}$ can credibly enforce $\mathbf{p}_{g, C^{L}}^{2}$. On the other hand, under a closed rule arrangement legislators $g_{d}, d>1$, can only approve or veto the policy chosen by $g_{1}$. Furthermore, since $v_{g_{d} g}^{2}\left(\mathbf{p}_{g, C}^{2}, T_{l g_{d}}^{2}\right)>$ 
$v_{g_{d} g}^{2}\left(\mathbf{p}_{0}^{2}\right) \forall \beta_{g_{d}}^{2}, C$, vetoing is not credible. As a consequence, if the lobby can induce the first legislator to choose $\mathbf{p}_{g, C^{H}}^{2}$, then it does not need to pay any positive transfer to convince $g_{d}$ with $d>1$ to pass $\mathbf{p}_{g, C^{H}}^{2}$. We can now determine the equilibrium transfers inducing the first legislator to choose $\mathbf{p}_{g, C^{H}}^{2}$. Let $r$ be the last round of negotiation between $g_{1}$ and $l$. Knowing that the two players can make a take-it-or-leave-it offer respectively with probability $q$ and $1-q, g_{1}$ receives $q \pi$ and $l$ receives $(1-q) \pi$. Moving to round $r-1$, the minimum payment that $g_{1}$ is willing to accept is $q \pi$ and similarly for $l$ it will be $(1-q) \pi$. The same is true moving backward until $r=1$, when the lobby $l$ offers $\mathbf{x}_{1}^{2}=\left(\mathbf{p}_{g, C^{H}}^{2}, T_{l g_{1}}^{2}=q \pi\right)$ and $g_{1}$ accepts. On the other hand, for $D=n$ the lobby makes take-it-or-leave-it offers $\mathbf{x}^{2}=\left(\mathbf{p}_{g, C^{H}}^{2}, T_{l g_{d}}^{2}=0\right)$ to each legislator $g_{d}, d>1$, which will be accepted since $v_{g_{d} g}^{2}\left(\mathbf{p}_{g, C^{H}}^{2}, T_{l g_{d}}^{2}=0\right)>v_{g_{d} g}^{2}\left(\mathbf{p}_{0}^{2}\right)$, while it offers $\mathbf{x}^{2}=\left(\mathbf{p}_{g, C^{H}}^{2}, T_{l g_{1}}^{2}=C^{H}\right)$ to legislator $g_{1}$ who accepts. Moving to $t=1$, when $D=n-k$, then $V_{g_{1}}\left(\mathbf{p}_{A, C^{H}}^{1}, T_{l g_{d}}^{1},.\right) \geq V_{g_{1}}\left(\mathbf{p}_{A, C^{L}}^{1}, T_{l g_{d}}^{1},.\right)$ if and only if he receives $\beta_{g_{1}}^{1} \geq \delta \beta_{g_{1}}^{2}+\frac{C^{H}+\delta\left(a_{A A}-a_{A B}\right)}{\pi}$, where $\beta_{g_{1}}^{2}=q$. Furthermore, $V_{g_{d}}\left(\mathbf{p}_{g_{d}, C^{H}}^{1}, T_{l g_{d}}^{1},.\right) \geq V_{g_{d}}\left(\mathbf{p}_{0}^{1},.\right)$, if and only if $\beta_{g_{d}}^{1} \geq \frac{\delta\left(a_{A A}-a_{A B}\right)}{\pi}+\frac{C^{H}-a_{A A}}{\pi}$. Hence, when $\frac{\delta\left(a_{A A}-a_{A B}\right)}{\pi}-\frac{C^{H}-a_{A A}}{\pi} \geq 0$ legislators $g_{d}, d>1$ can credibly threat to veto the proposal passed by $g_{1}$, unless they receive $\bar{\beta}_{g_{d}}^{1}=$ $\frac{\delta\left(a_{A A}-a_{A B}\right)}{\pi}+\frac{C^{H}-a_{A A}}{\pi}$. On the other hand, if $\frac{\delta\left(a_{A A}-a_{A B}\right)}{\pi}+\frac{C^{H}-a_{A A}}{\pi}<0, g_{d}$ cannot credibly veto any previously approved policy and therefore $\bar{\beta}_{g_{d}}^{1}=0 \forall d>1$. At the same time, when $D=n$ then $\beta_{g_{d}}^{2}=0 \forall d>1$, and $\beta_{g_{1}}^{2}=\frac{C^{H}}{\pi}$. Therefore $\bar{\beta}_{g_{1}}^{1}=\delta \frac{C^{H}}{\pi}+\frac{C^{H}+\delta\left(a_{A A}-a_{A B}\right)}{\pi}$, while $\bar{\beta}_{g_{d}}^{1}$ $\forall d>1$ is not affected.

\subsection{Proof of Lemma 5}

Proof. In $t=2$, since $v_{g_{d} g}^{2}\left(\mathbf{p}_{g C^{L}}^{2}\right)>v_{g_{d} g}^{2}\left(\mathbf{p}_{0}^{t}\right)$, in the absence of lobby transfers the first legislator chooses $\mathbf{p}_{g C^{L}}^{2}$ and the successive $d>1$ legislators ratify this choice. If amendment rights are restricted $(R=1)$, once policy $\mathbf{p}_{g C^{L}}^{2}$ is chosen by the first legislator, it can be amended to $\mathbf{p}_{g C^{H}}^{2}$ only if all legislators, including the first, approve the change. In the last stage $n$ the legislator $g_{D}$ and the lobby $l$ make take-it-or-leave-it offers with probability $q$ and $1-q$, and the agreement $\mathbf{x}_{n}^{2}=\left(\mathbf{p}_{g, C^{H}}^{2}, T_{l g_{D}}^{2}=q \pi_{g_{D-1}}\right)$ is reached provided that $q \pi_{g_{D-1}} \geq C^{H}$, where $\pi_{g_{D-1}}$ is the profit available to the lobby after it reached the agreement with the previous legislator $g_{D-1}$. Moving backward, during the first round of negotiation between $l$ and $g_{D}, l$ offers $\left(\mathbf{p}_{g C^{H}}^{2}, q \pi_{g_{D-1}}\right)$ and $g_{D}$ accepts. Similarly, during the first round of negotiation between $l$ and any $g_{d}, l$ offers $\left(\mathbf{p}_{g C^{H}}^{2}, q \pi_{g_{d-1}}\right)$ and $g_{d}$ accepts. Note that after 
each agreement with a legislator $d$ the lobby is left with a profit $(1-q)^{d-1} \pi$ that it can share with the subsequent legislator. Hence, each legislator obtains a share $q(1-q)^{d-1}$. Given that we have assumed that $q(1-q)^{D-1} \geq \frac{C^{H}}{\pi}$ then each legislator accepts the agreement $\mathbf{x}^{2}=\left(\mathbf{p}_{g, C^{H}}^{2}, T_{l g_{d}}^{2}=q(1-q)^{d-1} \pi\right)$ because the transfer exceeds his reservation value $C^{H}$. When amendment rights are unrestricted $(R=0)$, if the policy $\mathbf{p}_{g_{d} C^{L}}^{2}$ is chosen by all legislators $d<D$, the lobby can still obtain $\mathbf{p}_{g_{d} C^{H}}^{2}$ by just paying $\beta_{g_{D}}^{2}=q \pi$ to the last legislator $g_{D}$. Hence, the lobby will offer $\mathbf{x}_{g_{d}}^{2}=\left(\mathbf{p}_{g_{d} C^{L}}^{2}, T_{l g_{d}}^{2}=0\right)$ to $g_{d}$ with $d<D$ who will accept because $v_{g_{d} g}^{2}\left(\mathbf{p}_{g C^{L}}^{2}\right)>v_{g_{d} g}^{2}\left(\mathbf{p}_{0}^{t}\right)$, and $\mathbf{x}_{g_{D}}^{2}=\left(\mathbf{p}_{g_{D} C^{H}}^{2}, T_{l g_{D}}^{2}=q \pi\right)$ to the last legislator $g_{D}$ who accepts. In $t=1$ for each legislator $g_{d}$ the payoff from $\mathbf{p}_{A, C^{H}}^{1}$ is $V_{g_{d}}\left(\mathbf{p}_{A, C^{H}}^{1}, T_{l g_{d}}^{1},.\right)=a_{A A}+$ $\beta_{g_{d}}^{1} \pi-C^{H}+\delta\left(a_{A B}-C^{H}\right)$ and the payoff from $\mathbf{p}_{A, C^{L}}^{1}$ is $V_{g_{d}}\left(\mathbf{p}_{A, C^{L}}^{1},.\right)=a_{A A}+\delta\left(a_{A A}+\beta_{g d}^{2} \pi-C^{H}\right)$. Since $\beta_{g_{d}}^{2}=R q(1-q)^{d-1}+g(d, R) \delta q$, we find that $V_{g_{d}}\left(\mathbf{p}_{A, C^{H}}^{1}, T_{l g_{d}}^{1},.\right) \geq V_{g_{d}}\left(\mathbf{p}_{A, C^{L}}^{1},.\right)$ if and only if $\beta_{g_{d}}^{1} \geq R \delta q(1-q)^{d-1}+g(d, R) \delta q+\frac{C^{H}+\delta\left(a_{A A}-a_{A B}\right)}{\pi}$.

\subsection{Proof of Theorem 1}

Proof. Given $\beta_{l}^{1} \geq \delta\left(\frac{a_{l A}-a_{l B}}{\pi}\right)$, lemmata 1-3 imply that if the minimum shares required by a single and by $D$ chambers to choose $\mathbf{p}_{A, C^{H}}^{1}$ are feasible, then $\mathbf{p}_{A, C^{H}}^{1}$ is chosen. On the other hand, when the minimum shares are not feasible, then $\mathbf{p}_{A, C^{L}}^{1}$ is chosen. These minimum shares are $\bar{\beta}_{A, n}^{1}=D \delta \frac{\left(a_{A A}-a_{A B}\right)}{\pi}+\frac{(D+\delta) C^{H}-(D-1) a_{A A}}{\pi}, \bar{\beta}_{A, n-k}^{1}=\delta q+D \delta \frac{\left(a_{A A}-a_{A B}\right)}{\pi}+\frac{D C^{H}-(D-1) a_{A A}}{\pi}$ and $\bar{\beta}_{A}^{1}=\delta q+\frac{C^{H}+\delta\left(a_{A A}-a_{A B}\right)}{\pi}$ with respectively $D$ and one legislator. First note that from assumption 1 we have that $\bar{\beta}_{A, n-k}^{1}>\bar{\beta}_{A}^{1}$, and if $\bar{\beta}_{A, n-k}^{1}<1$, then both $\bar{\beta}_{A, n-k}^{1}$ and $\bar{\beta}_{A}^{1}$ are feasible. Similarly, if the smallest share $\bar{\beta}_{A}^{1}$ is not feasible, the biggest share $\bar{\beta}_{A, n-k}^{1}$ will also not be feasible. When on the other hand $\bar{\beta}_{A}^{1}<1<\bar{\beta}_{A, n-k}^{1}$, then $\bar{\beta}_{A}^{1}$ only is feasible. Noting also that $\bar{\beta}_{A, n}^{1} \lesseqgtr \bar{\beta}_{A}^{1}$ the following can be established. If $\bar{\beta}_{A, n}^{1}<1<\bar{\beta}_{A}^{1}$, only the share with two legislators is feasible; when $\bar{\beta}_{A, n}^{1}<\bar{\beta}_{A}^{1}<1$ both shares are feasible; when $1<\bar{\beta}_{A, n}^{1}<\bar{\beta}_{A}^{1}$ , none of the shares is feasible, while when $\bar{\beta}_{A}^{1}<1<\bar{\beta}_{A, n}^{1}$ only the share with a single legislator is feasible.

\subsection{Proof of Theorem 2}

Proof. Suppose that lemma 5 holds. When $R=1$ given that $\mathbf{p}_{A, C^{H}}^{1}$ is the best policy for the lobby group (i.e. $\left.\beta_{l}^{1} \geq \delta\left(\frac{a_{l A}-a_{l B}}{\pi}\right)\right)$ if the sum of the minimum shares is feasible $\left(\sum_{d=1}^{D} \bar{\beta}_{g_{d}}^{1} \leq 1\right)$ then $\mathbf{p}_{A, C^{H}}^{1}$ is chosen. On the other hand, if $\sum_{d=1}^{D} \bar{\beta}_{g_{d}}^{1}>1$ then $V_{g_{d} A}\left(\mathbf{p}_{A, C^{H}}^{1},.\right)<V_{g_{d} A}\left(\mathbf{p}_{0}^{1},.\right)<$ 
$V_{g_{d} A}\left(\mathbf{p}_{A, C^{L}}^{1},.\right) \forall d$ implies that $\mathbf{p}_{A, C^{L}}^{1}$ is chosen. Since the sum of the minimum shares under open rule is bigger than under closed rule, then: (a) whenever the the sum of the minimum shares is not feasible under closed rule, it will also not be feasible under open rule; (b) When the sum of the minimum share is feasible under closed rule, it may not be feasible under open rule. From (a) and (b) we conclude that whenever the low cost policy is chosen under closed rule it will also be chosen under open rule, while the reverse is not true.

Consider now the case where $R=0$. The last legislator will exert his amendment right only if there is a feasible agreement he prefers over the initial agreement reached by the lobby and the previous legislators. Again, as $\mathbf{p}_{A, C^{H}}^{1}$ is the best policy for the lobby group when $\sum_{d=1}^{D} \bar{\beta}_{g_{d}}^{1} \leq 1$, then from lemma 5 we know that $\mathbf{p}_{A, C^{H}}^{1}$ is chosen by $g_{d}$ with $d<D$, and is ratified by the last legislator $g_{D}$. On the other hand, if the transfer necessary to induce $g_{D}$ to choose $\mathbf{p}_{A, C^{H}}^{1}$ is not feasible, i.e. if $\bar{\beta}_{A}^{1}>1$, then $\mathbf{p}_{A, C^{L}}^{1}$ is chosen. Given that the sum of the minimum shares is the same under open and closed rule, whenever the sum of the shares is feasible, the high cost policy is chosen under both open and closed rule. Similarly, if none of the individual shares is feasible, then the low cost is chosen again under both open and closed rule. Suppose now that the sum of the equilibrium transfers required by the $D$ legislators exceeds the lobby profit, $\delta q+D\left[\frac{C^{H}+\delta\left(a_{A A}-a_{A B}\right)}{\pi}\right]>1$, but that each individual transfer is less than the profit, $\delta q+\frac{C^{H}+\delta\left(a_{A A}-a_{A B}\right)}{\pi}<1$. In this case, the first legislator could choose $\mathbf{p}_{g, C^{H}}^{1}$ if he is offered the appropriate transfer. However, given that legislators $d>1$ cannot all be offered the transfer necessary to pass $\mathbf{p}_{g, C^{H}}^{1}$, the lobby will not find it optimal to carry out the transfer necessary to obtain $\mathbf{p}_{g_{1}, C^{H}}^{1}$ in the first legislative step, knowing that this proposal will be overridden by some of the subsequent legislators. As a consequence, the lobby offers $\left(\mathbf{p}_{g_{1}, C^{L}}^{1}, T_{l g_{1}}^{1}=0\right)$ to the first legislator, who will then decide whether to choose $\mathbf{p}_{g_{1}, C^{L}}^{1}$ or reject (i.e. keep the status quo $\mathbf{p}_{0}^{1}$ ). Since the first legislator anticipates that $\mathbf{p}_{g_{1}, C^{L}}^{1}$ will be overridden by the last legislator who can receive the appropriate rent share for choosing $\mathbf{p}_{g_{D}, C^{H}}^{1}$, and $V_{g_{1} A}\left(\mathbf{p}_{0}^{1}\right) \geq V_{g_{1} A}\left(\mathbf{p}_{A, C^{H}}^{1}\right) \forall \delta \geq \hat{\delta}$, then $g_{1}$ rejects the offer since since by assumption $1 \delta \geq \hat{\delta}$. In every subsequent negotiation round between the first legislator and the lobby, with probability $(1-q)$ the lobby offers again $\left(\mathbf{p}_{g_{1}, C^{L}}^{1}, T_{l g_{1}}^{1}=0\right)$ to the legislator who rejects, and with probability $q$ the legislators offers $\left(\mathbf{p}_{g_{1}, C^{H}}^{1}, T_{l_{1}}^{1}>0\right)$ to the lobby who rejects since she cannot afford paying the subsequent legislator the minimum transfer required to pass the high cost policy. Hence, the bargaining between the lobby and the first legislator ends with no policy implemented. As a consequence, subsequent legislators without 
proposal power will not be able to amend any proposal, and the mandate terminates with no policy implemented. The observation that under closed rule, if $\delta q+D\left[\frac{C^{H}+\delta\left(a_{A A}-a_{A B}\right)}{\pi}\right]>1$ and $\delta q+\frac{C^{H}+\delta\left(a_{A A}-a_{A B}\right)}{\pi}<1$, then the low cost policy is chosen establishes part (ii) of the theorem.

\section{References}

Alesina, A. (1988). Credibility and policy convergence in a two-party system with rational voters. The American Economic Review 78, 796-805.

Ansolabehere, S., J. M. Snyder Jr, and C. Stewart III (2001). Candidate positioning in the US House election. American Journal of Political Science 45, 136-159.

Baron, D. and J. Ferejohn (1989). Bargaining in legislatures. American Political Science Review 83, 1181-1206.

Bernheim, B. D., A. Rangel, and L. Rayo (2006). The power of the last word in legislative policy making. Econometrica 74, 1161-1190.

Besley, T. and S. Coate (1997). An economic model of representative democracy. Quarterly Journal of Economics 112, 85-114.

Besley, T. and S. Coate (2003). Elected versus appointed regulators: Theory and evidence. Journal of the European Economic Association 1, 1176-1206.

Bradubury, J. C. and W. M. Crain (2001). Legislative organization and government spending: Cross-country evidence. Journal of Public Economics 82, 309-332.

Corporate Crime Reporter (2004). Public corruption in the united states. pp. 1-16.

Diermeier, D., H. Erasalan, and A. Merlo (2003). A structural model of government formation. Econometrica $71,27-70$.

Diermeier, D. and R. B. Myerson (1999). Bicameralism and its consequences for the internal organization of legislatures. American Economic Review 89, 1182-1196.

Druckman, J. N. and M. Thies (2002). The importance of concurrence: The impact of bicameralism on government formation and duration. American Journal of Political Science, $760-771$. 
Eckl, C. (1998). Late state budgets. NCSL Legisbrief 6, no.14.

Ewing, C. M. D. (1937). Lobbying in nebraska' legislature. The Public Opinion Quarterly 2, 103-104.

Ferejohn, J. (1986). Incumbent performance and electoral control. Public Choice 50, 5-25.

Fiorina, M. P. (1981). Retrospective voting in American national elections. New Haven, CT: Yale University Press.

Glaeser, E. L. and R. E. Saks (2006). corruption in America. Journal of Public Economics 90, 1053-1072.

Groseclose, T. (2007). 'One and a half dimensional' preferences and majority rule. Social Choice and Welfare 28, 321-335.

Groseclose, T. and J. Snyder (1996). Buying supermajorities. American Political Science Review 90, 303-315.

Grossman, G. and E. Helpman (1996). Electoral competition and special interests politics. Review of Economic Studies 63, 265-86.

Heller, W. B. (2001). Political denials: The policy effect of intercameral partisan differences in bicameral parliamentary systems. Journal of Law, Economics and Organizations (17), 34-61.

Jacobs, L. R. and R. Y. Shapiro (2000). Politicians don't Pander. The University of Chicago Pres.

Kolasa, B. D. (1971). Lobbying in the nonpartisan environment: the case of nebraska. The Public Opinion Quarterly 24, 65-78.

Levitt, S. D. (1996). How do senators vote? disentangling the role of voters' preferences, party affiliation and senators ideology. American Economic Review 86, 425-441.

Levmore, S. (1992). Bicameralism: When are two decisions bettern than one. International Review of Law and Economics 12, 145-162.

Madison, J. (1788). Federalist Paper 62. In J. Jay, A. Hamilton, and J. Madison (Eds.), The Federalist or the new Constitution. London: Everyman Edition.

McKelvey, R. D. and R. Riezman (1992). Seniority in legislatures. The American Political Science review 86, 951-965. 
Muthoo, A. and K. A. Shepsle (2008). The constitutional choice of bicameralism. In E. Helpman (Ed.), Institutions and Economics Performance. Cambridge, MA: Harvard University Press.

NASBO (2002). Budget processes in the state. National Association of State Budget Officers January, 1-100.

Osborne, M. and A. Rubinstein (1990). Bargaining and Markets. San Diego: Academic Press.

Osborne, M. and A. Slivinski (1996). A model of political competition with citizen candidates. Quarterly Journal of Economics 111, 65-96.

Persson, T., G. Roland, and G. Tabellini (1997). Separation of powers and political accountability. Quarterly Journal of Economics 112, 1163-1202.

Poole, K. T. and H. Rosenthal (1996). Are legislators ideologues or agents of constituents? European Economics Review 40, 707-717.

Riker, W. H. (1992). the justification of bicameralism. nternational Political Science Review 12, 101-116.

Rogers, J. M. (1999). Judicial review standards in unicameral legislative systems: A positive theoretic and historic analysis. Creighton Law Review 33, 65-120.

Shumate, R. V. (1952). The nebraska unicameral legislature. The Public Opinion Quarterly 52, 504-512.

Testa, C. (2003). Do candidates serve party interests? Party polarisation as a discipline device. Discussion paper 2003-13, Royal Holloway.

Testa, C. (2009). Bicameralism and corruption. European Economic Review forthcoming. Tsebelis, G. and J. Money (1997). Bicameralism. Cambridge, UK: Cambdrige University Press.

Ventura, J. (1998). Jesse Ventura on Government Reform. On the issues: Every political leader on every issue. www.ontheissues.org. 


\section{CESifo Working Paper Series}

for full list see www.cesifo-group.org/wp

(address: Poschingerstr. 5, 81679 Munich, Germany, office@cesifo.de)

2597 Carsten Eckel, International Trade and Retailing, March 2009

2598 Gianni De Nicolò and Iryna Ivaschenko, Global Liquidity, Risk Premiums and Growth Opportunities, March 2009

2599 Jay Pil Choi and Heiko Gerlach, International Antitrust Enforcement and Multi-Market Contact, March 2009

2600 Massimo Bordignon and Guido Tabellini, Moderating Political Extremism: Single Round vs Runoff Elections under Plurality Rule, April 2009

2601 Ana B. Ania and Andreas Wagener, The Open Method of Coordination (OMC) as an Evolutionary Learning Process, April 2009

2602 Simon Gächter, Daniele Nosenzo, Elke Renner and Martin Sefton, Sequential versus Simultaneous Contributions to Public Goods: Experimental Evidence, April 2009

2603 Philippe Jehiel and Andrew Lilico, Smoking Today and Stopping Tomorrow: A Limited Foresight Perspective, April 2009

2604 Andreas Knabe, Steffen Rätzel, Ronnie Schöb and Joachim Weimann, Dissatisfied with Life, but Having a Good Day: Time-Use and Well-Being of the Unemployed, April 2009

2605 David Bartolini and Raffaella Santolini, Fiscal Rules and the Opportunistic Behaviour of the Incumbent Politician: Evidence from Italian Municipalities, April 2009

2606 Erkki Koskela and Jan König, Can Profit Sharing Lower Flexible Outsourcing? A Note, April 2009

2607 Michel Beine, Frédéric Docquier and Çağlar Özden, Diasporas, April 2009

2608 Gerd Ronning and Hans Schneeweiss, Panel Regression with Random Noise, April 2009

2609 Adam S. Booij, Bernard M.S. van Praag and Gijs van de Kuilen, A Parametric Analysis of Prospect Theory's Functionals for the General Population, April 2009

2610 Jeffrey R. Brown, Julia Lynn Coronado and Don Fullerton, Is Social Security Part of the Social Safety Net?, April 2009

2611 Ali Bayar and Bram Smeets, Economic, Political and Institutional Determinants of Budget Deficits in the European Union, April 2009 
2612 Balázs Égert, The Impact of Monetary and Commodity Fundamentals, Macro News and Central Bank Communication on the Exchange Rate: Evidence from South Africa, April 2009

2613 Michael Melvin, Christian Saborowski, Michael Sager and Mark P. Taylor, Bank of England Interest Rate Announcements and the Foreign Exchange Market, April 2009

2614 Marie-Louise Leroux, Pierre Pestieau and Gregory Ponthiere, Should we Subsidize Longevity?, April 2009

2615 Ronald MacDonald, Lukas Menkhoff and Rafael R. Rebitzky, Exchange Rate Forecasters' Performance: Evidence of Skill?, April 2009

2616 Frederick van der Ploeg and Steven Poelhekke, The Volatility Curse: Revisiting the Paradox of Plenty, April 2009

2617 Axel Dreher, Peter Nunnenkamp, Hannes Öhler and Johannes Weisser, Acting Autonomously or Mimicking the State and Peers? A Panel Tobit Analysis of Financial Dependence and Aid Allocation by Swiss NGOs, April 2009

2618 Guglielmo Maria Caporale, Roman Matousek and Chris Stewart, Rating Assignments: Lessons from International Banks, April 2009

2619 Paul Belleflamme and Martin Peitz, Asymmetric Information and Overinvestment in Quality, April 2009

2620 Thomas Dohmen, Armin Falk, David Huffman and Uwe Sunde, Are Risk Aversion and Impatience Related to Cognitive Ability?, April 2009

2621 Yin-Wong Cheung and Xingwang Qian, The Empirics of China's Outward Direct Investment, April 2009

2622 Frédérique Bec and Christian Gollier, Assets Returns Volatility and Investment Horizon: The French Case, April 2009

2623 Ronnie Schöb and Marcel Thum, Asymmetric Information Renders Minimum Wages Less Harmful, April 2009

2624 Martin Ruf and Alfons J. Weichenrieder, The Taxation of Passive Foreign Investment Lessons from German Experience, April 2009

2625 Yao Li, Borders and Distance in Knowledge Spillovers: Dying over Time or Dying with Age? - Evidence from Patent Citations, April 2009

2626 Jim Malley and Ulrich Woitek, Technology Shocks and Aggregate Fluctuations in an Estimated Hybrid RBC Model, April 2009

2627 Jin Cao and Gerhard Illing, Endogenous Systemic Liquidity Risk, April 2009 
2628 Thiess Buettner and Bjoern Kauder, Revenue Forecasting Practices: Differences across Countries and Consequences for Forecasting Performance, April 2009

2629 Håkan Selin, The Rise in Female Employment and the Role of Tax Incentives - An Empirical Analysis of the Swedish Individual Tax Reform of 1971, April 2009

2630 Nick Johnstone and Ivan Hascic, Environmental Policy Design and the Fragmentation of International Markets for Innovation, April 2009

2631 Spiros Bougheas, Richard Kneller and Raymond Riezman, Optimal Education Policies and Comparative Advantage, April 2009

2632 Jay Pil Choi and Heiko Gerlach, Multi-Market Collusion with Demand Linkages and Antitrust Enforcement, April 2009

2633 Thor O. Thoresen, Income Mobility of Owners of Small Businesses when Boundaries between Occupations are Vague, April 2009

2634 Guido Schwerdt and Amelie C. Wuppermann, Is Traditional Teaching really all that Bad? A Within-Student Between-Subject Approach, April 2009

2635 Kurt R. Brekke, Luigi Siciliani and Odd Rune Straume, Hospital Competition and Quality with Regulated Prices, April 2009

2636 Peter Diamond, Taxes and Pensions, April 2009

2637 Shoshana Grossbard, How "Chicagoan” are Gary Becker's Economic Models of Marriage?, May 2009

2638 Roland Strausz, Regulatory Risk under Optimal Incentive Regulation, May 2009

2639 Holger Zemanek, Ansgar Belke and Gunther Schnabl, Current Account Imbalances and Structural Adjustment in the Euro Area: How to Rebalance Competitiveness, May 2009

2640 Harald Hau and Marcel Thum, Subprime Crisis and Board (In-)Competence: Private vs. Public Banks in Germany, May 2009

2641 Martin Halla, Mario Lackner and Friedrich G. Schneider, An Empirical Analysis of the Dynamics of the Welfare State: The Case of Benefit Morale, May 2009

2642 Balázs Égert, Infrastructure Investment in Network Industries: The Role of Incentive Regulation and Regulatory Independence, May 2009

2643 Christian Gollier, Expected Net Present Value, Expected Net Future Value, and the Ramsey Rule, May 2009

2644 Sören Blomquist and Håkan Selin, Hourly Wage Rate and Taxable Labor Income Responsiveness to Changes in Marginal Tax Rates, May 2009 
2645 Dominique Demougin, Oliver Fabel and Christian Thomann, Implicit vs. Explicit Incentives: Theory and a Case Study, May 2009

2646 Francesco C. Billari and Vincenzo Galasso, What Explains Fertility? Evidence from Italian Pension Reforms, May 2009

2647 Kjell Arne Brekke, Karen Evelyn Hauge, Jo Thori Lind and Karine Nyborg, Playing with the Good Guys - A Public Good Game with Endogenous Group Formation, May 2009

2648 Guglielmo Maria Caporale and Luis A. Gil-Alana, Multi-Factor Gegenbauer Processes and European Inflation Rates, May 2009

2649 Henning Bohn, A Static Model for Voting on Social Security, May 2009

2650 Markus Haavio and Kaisa Kotakorpi, The Political Economy of Sin Taxes, May 2009

2651 Augusto de la Torre, María Soledad Martínez Pería and Sergio L. Schmukler, Drivers and Obstacles to Banking SMEs: The Role of Competition and the Institutional Framework, May 2009

2652 Tobias Lindhe and Jan Södersten, Dividend Taxation, Share Repurchases and the Equity Trap, May 2009

2653 Assaf Razin and Edith Sand, Migration-Regime Liberalization and Social Security: Political-Economy Effect, May 2009

2654 Yin-Wong Cheung and Hiro Ito, A Cross-Country Empirical Analysis of International Reserves, May 2009

2655 Bart Cockx and Bruno Van der Linden, Flexicurity in Belgium. A Proposal Based on Economic Principles, May 2009

2656 Michael Melvin, Lukas Menkhoff and Maik Schmeling, Exchange Rate Management in Emerging Markets: Intervention via an Electronic Limit Order Book, May 2009

2657 Susanne Neckermann, Reto Cueni and Bruno S. Frey, What is an Award Worth? An Econometric Assessment of the Impact of Awards on Employee Performance, May 2009

2658 Steven Brakman, Harry Garretsen and Charles van Marrewijk, Economic Geography within and between European Nations: The Role of Market Potential and Density across Space and Time, May 2009

2659 Giovanni Facchini and Cecilia Testa, Reforming Legislatures: Is one House better than two?, May 2009 